\title{
Partial loss of colonic primary cilia promotes inflammation and \\ carcinogenesis
}

\author{
Ruizhi Tang ${ }^{1 \#}$, Conception Paul ${ }^{1 \#}$, Rossano Lattanzio², Thibaut Eguether ${ }^{3}$, Hulya \\ Tulari $^{1}$, Julie Bremond ${ }^{1}$, Chloé Maurizy ${ }^{1}$, Sophie Poupeau ${ }^{1}$, Andrei Turtoi ${ }^{4}$, Magali \\ Svrcek $^{5}$, Philippe Seksik ${ }^{3}$, Vincent Castronovo ${ }^{6}$, Philippe Delvenne $^{7}$, Bénédicte \\ Lemmers $^{1}$, Carsten Janke ${ }^{8}$, Valérie Pinet ${ }^{1 \star \$}$ and Michael Hahne ${ }^{1 \star \$}$ \\ ${ }^{1}$ Institut de Génétique Moléculaire de Montpellier, Univ Montpellier, CNRS, Montpellier, \\ France \\ ${ }^{2}$ Department of Medical, Oral and Biotechnological Sciences, Center for Advanced Studies \\ and Technology (CAST), 'G. d'Annunzio' University of Chieti-Pescara, Chieti, Italy. \\ ${ }^{3}$ Sorbonne Université, INSERM S 938, AP-HP, Centre de recherche Saint Antoine, Equipe \\ 13, Paris, France \\ ${ }^{4}$ Tumor Microenvironment and Resistance to Treatment Laboratory, Institut de Recherche \\ en Cancérologie de Montpellier, Montpellier, France \\ ${ }^{5}$ Sorbonne Université, Department of Pathology, AP-HP, Hôpital Saint-Antoine, Paris, \\ France \\ ${ }^{6}$ Metastasis Research Laboratory, GIGA Cancer, University of Liège, Liège, Belgium \\ ${ }^{7}$ Department of Pathology, University Hospital (CHU), University of Liège, Liège, Belgium \\ ${ }^{8}$ Institut Curie, Paris Sciences et Lettres (PSL) Research University, Centre National de la \\ Recherche Scientifique (CNRS) Unité Mixte de Recherche (UMR) 3348, F-91405 Orsay, \\ France; Université Paris Sud, Université Paris-Saclay, CNRS UMR 3348, F-91405 Orsay, \\ France
}

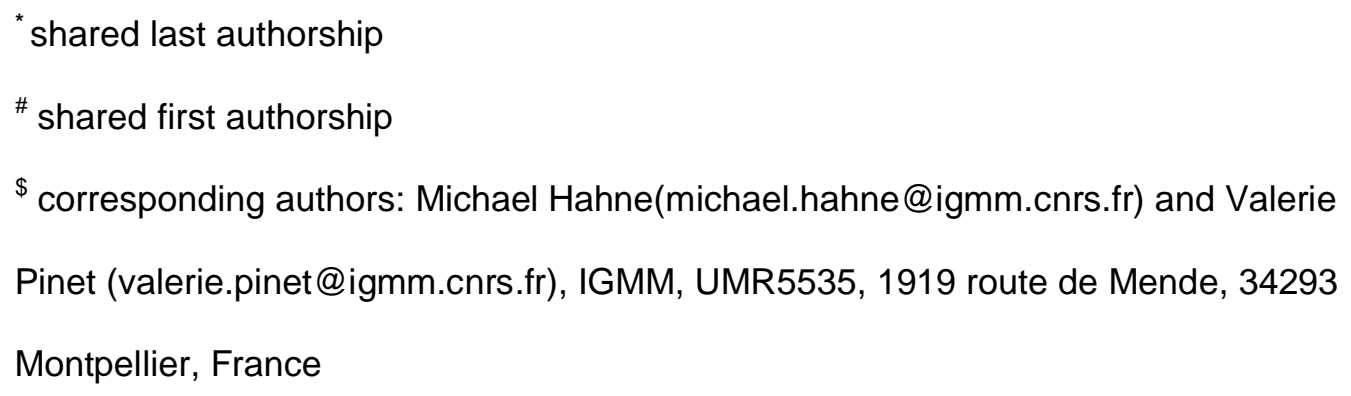

The authors declare to have no conflict of interest.

Keywords: Primary cilia, colitis, colon carcinogenesis, colonic fibroblasts, inflammation 


\section{Abstract}

Primary cilia (PC) are important signaling hubs in cells and their deregulation has been associated with various diseases including cancer. Here we explored the role of PC in colorectal cancer (CRC) and colitis. In the colon we found PC to be mostly present on different subtypes of fibroblasts. Colons of mice exposed to either chemically induced colitisassociated colon carcinogenesis (CAC) or dextran sodium sulfate (DSS)-induced colitis had decreased numbers of PC. We employed conditional knock-out strains for the PC essential genes, Kif3A and Ift88, to generate mice with reduced numbers of PC on colonic fibroblasts. These mice showed an increased susceptibility in the CAC model as well as in DSS-induced colitis. Colons from DSS-treated mice with PC-deficiency on fibroblasts displayed an elevated production of the pro-inflammatory cytokine IL-6 and colonic epithelial cells had diminished levels of HES-1, a key transcription factor of Notch signaling. Notably, an analysis of PC presence on biopsies of patients with ulcerative colitis as well as CRC patients revealed decreased numbers of $P C$ on colonic fibroblasts in pathological versus surrounding normal tissue. Taken together, we provide evidence that a decrease in colonic PC numbers promotes colitis and CRC. 


\section{Graphical Abstract}

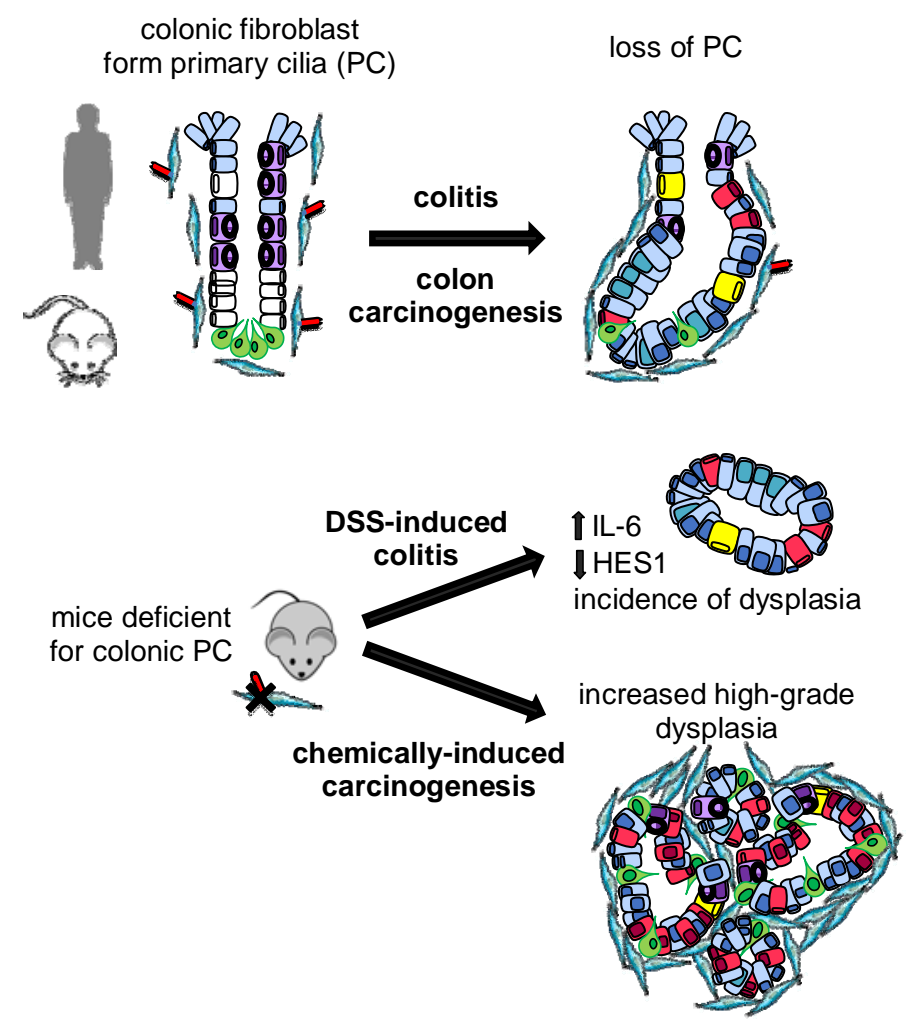




\section{Introduction}

Colorectal cancer $(\mathrm{CRC})$ is the third most common and deadly cancer worldwide (Malvezzi et al, 2018). Due to its asymptomatic nature, CRC is frequently diagnosed only after the cancer has spread through the colon or rectal wall (stage II), to the lymph nodes (stage III) and/or to distant organs (stage IV), e.g. liver, lung and peritoneum. CRC is a molecularly highly heterogeneous disease and there is an urgent need to map the heterogeneity of $\mathrm{CRC}$, to identify novel therapeutic intervention points as well as novel prognostic and predictive biomarkers that pre-select stage II and III CRC patients who will not benefit from standard-of-care chemotherapy, re-directing them towards novel, targeted treatment options. In addition, clinical studies demonstrate that innate and/or acquired tumor resistance remains a core problem in the management of stage IV CRC patients, further highlighting the need to develop biomarker-guided therapeutic approaches for treatment of those patients.

A recent meta-analysis on the different reported sub-classifications defined the existence of at least 4 distinct gene expression-based CRC subtypes, called Consensus Molecular Subtypes (CMS) 1-4, each displaying unique biology and gene expression pattern (Guinney et al, 2015). Among those CMS4 cancers have the worst prognosis and are characterized by a stromal and inflammatory gene signature (Becht et al, 2016). The importance of inflammation during tumorigenesis is well illustrated by the fact that tissues with chronic inflammation have an increased risk to develop tumors (Grivennikov et al, 2009). Hence, patients with inflammatory bowel disease have a higher probability to develop CRC (Beaugerie et al, 2017).

A master regulator of signaling pathways are primary cilia (PC), which are supposed to extrude most mammalian cells and act as sensory antennae (Gerdes et al, 2009). PC contain a scaffold of nine microtubule (MT) doublets forming a cylinder-like arrangement in the plasma membrane by a basal body that derives from a centriole. PC are involved in a variety of diseases commonly referred to as ciliopathies including cystic kidney diseases (Ko \& Park, 2013), but they are also involved in tumor formation (Han et al, 2009)(Wong et al, 2009). In fact, a picture is emerging that there is an important inter- and intra-tumoral variation of PC numbers (Liu et al, 2018)(Eguether \& Hahne, 2018). PC properties can be modulated by post-translational modifications (PTMs) of tubulin including acetylation and glycylation (Wloga et al, 2017). For example, it has been shown that blocking of deacetylation induces cilia restoration and decreases tumor growth of cholangiocarcinoma (Gradilone et al, 2013). We previously described an unexpected role of the tubulin glycylase TTLL3 in the regulation of colon tumorigenesis (Rocha et al, 2014). Specifically, we discovered that TTLL3 is the only glycylase expressed in the colon and that the absence of 
TTLL3 leads to decreased numbers of PC in colonic crypts (Rocha et al, 2014). When exposed to chemically induced colon carcinogenesis, $\mathrm{Tt} / \mathrm{l}^{/-}$mice are more susceptible to tumor formation (Rocha et al, 2014). Importantly, TTLL3 expression levels were significantly downregulated in human primary colorectal carcinomas and metastases as compared to healthy colon tissue, strongly suggesting a pivotal role of TTLL3 in colorectal cancer. All together, these findings revealed a first direct link between the downregulation of PC and colon carcinogenesis.

In this study, we directly investigated the role of PC in colon carcinogenesis by employing relevant mouse models and analysis of patient biopsies. 


\section{Results}

\section{Colonic fibroblasts form primary cilia}

To characterize the presence of PC in the colon we employed a previously described protocol that allows the detection of PC on paraffin-embedded tissues (Hassounah et al, 2013). Co-staining was performed combining the established PC marker Arl13b (Caspary et al, 2007) with markers for epithelial or stromal cells including E-cadherin, vimentin, alphasmooth muscle actin (a-SMA) and CD140a (platelet-derived growth factor receptor alpha). Staining for vimentin and a-SMA allows to distinguish fibroblasts from myofibroblasts, whereas CD140a characterizes a recently described vimentin ${ }^{\text {low }}$ a-SMA ${ }^{\text {negative }}$ subpopulation of fibroblasts present on the upper parts of the crypts (Roulis \& Flavell, 2016)(Kurahashi et al, 2013) (Figures 1 B-D). While only few epithelial cells displayed detectable PC (Figure $1 \mathrm{~A}$ and supplementary Figure S1), PC were mostly found on vimentin ${ }^{\text {positive }}$ or CD140a ${ }^{\text {positive }}$ stromal cells in the lamina propia (Figures 1B-D), but also on a-SMA ${ }^{+}$myofibroblasts (Figure 1D, E).

Progressive loss of colonic primary cilia during colon carcinogenesis

To determine whether decreased numbers of PC promote colon carcinogenesis we first analyzed the presence of PC in a mouse model that mimics colitis-associated colon carcinogenesis (CAC) (Tanaka et al, 2003)(Suzuki et al, 2004). This model depends on the administration of the mutagen azoxymethane (AOM) and the subsequent induction of inflammation with dextran sodium sulfate (DSS) (Figure 2A). DSS is toxic to mucosal epithelial cells in the colon, and the ensuing breakdown of the mucosal barrier leads to inflammation. Colonic crypts displayed a lower number of PC on vimentin ${ }^{\text {positive }}$ cells in tumor lesions as compared to adjacent normal tissue (Figures 2B,C). Remarkably, areas with highgrade dysplasia showed significant lower numbers of PC than those with low-grade dysplasia. Taken together, CAC is associated with a down-regulation of PC, confirming our initial hypothesis.

\section{Decreased numbers of primary cilia in colonic fibroblasts promote CAC}

To establish a causal relationship of PC on colonic fibroblasts and the development of $\mathrm{CRC}$, we employed a mouse strain carrying conditional knockout (KO) alleles for the kinesin family member 3A (Kif3a ${ }^{f / x / f / x}$ ) (Marszalek et al, 1999), a protein essential for cilia formation. Tissue-specific deletion of this gene in mesenchymal cells, including intestinal fibroblasts, was achieved in combination with ColVI-cre transgenic mice, expressing Cre DNArecombinase under the control of a collagenase VI promoter (Armaka et al, 2008)(Koliaraki et 
al, 2015)(Roulis \& Flavell, 2016). ColVIcre-Kif3a ${ }^{f(x / f l x}$ mice were fertile, born at the expected mendelian ratio and displayed no overt intestinal phenotype (Figure 3A,B). Kif3a-deletion was indeed only detectable in intestinal fibroblasts, but not epithelial cells (Supplementary Figure S2A) and resulted in significantly less PC in the colon of ColVIcre-Kif3a $a^{f l x f l x}$ mice, although the depletion of PC on vimentin ${ }^{\text {positive }}$ and CD140 $\alpha^{\text {positive }}$ colonic fibroblasts was only partial $(30-40 \%$, Figures 3C,D). This is in line with a previous report that the ColVI promoter is active only in a part of vimentin ${ }^{\text {positive }}$ or CD140a ${ }^{\text {positive }}$ colonic fibroblasts (Koliaraki et al, 2015). Moreover, biological and clinical differences for different segments of the colon have been described (Minoo et al, 2010), but the decrease of PC numbers ColVIcre-Kif3a ${ }^{f(x / f l x}$ mice is consistent across distal, transversal and proximal regions of the colon (Supplementary Figure 2B).

We next tested whether the reduced number of PC in the colon of ColVIcre-Kif3a $a^{f f(f l x}$ mice alters their susceptibility to AOM/DSS-induced carcinogenesis. Female ColVIcreKif3 $a^{f(x / f l x}$ mice displayed an increased incidence of dysplasia, in particular, a higher number of high-grade dysplasia as compared to Kif3a $a^{f(x / f x}$ mice (Figures 3E,F,G). Male mice are known to be more susceptible to colon carcinogenesis than females (Lee et al, 2016) and indeed, following the AOM/DSS treatment we observed a survival rate of about $35 \%$ of ColVIcre-Kif3a ${ }^{f / x / f l x}$ males in contrast to $100 \%$ of controls (Figure $3 \mathrm{H}$ ). Thus, PC deficiency in colonic fibroblasts enhances the sensitivity of mice to colitis-associated carcinogenesis.

\section{Mice deficient of primary cilia are more susceptible to DSS-induced colitis}

AOM/DSS treated male ColVIcre-Kif3 ${ }^{f(x) f l x}$ mice displayed a significantly lower weight during the first and third treatment of DSS (Supplementary Figure S3). Moreover, the ColVIcre-Kif3 $a^{f / x / f l x}$ mice that died during the AOM/DSS protocol manifested severe signs of crypt loss, suggesting to be the cause of death as can be observed in severe cases of inflammatory bowel disease (Eichele \& Kharbanda, 2017). These observations inspired us to test the impact of decreased numbers of colonic PC in inflammation. To this aim, ColVIcreKif3 $a^{f(x / f l x}$ and control mice were treated for one week with DSS (Figure 4A), a commonly used animal model for acute colitis (Wirtz et al, 2007)(Hao et al, 2015). In fact, ColVIcreKif3 ${ }^{f f(f f l x}$ mice displayed a significantly higher weight loss than Kif3a ${ }^{f f(f f x}$ mice at days 7, 8 and 9 after the start of the protocol (Figure 4B). Concurring with the more pronounced weight loss, colons of ColVIcre-Kif3a ${ }^{f(x / f l x}$ mice displayed larger areas of crypt loss and architectural irregularities (Figures $4 \mathrm{C}, \mathrm{D}, \mathrm{E}$ ). Notably, 4 out of 7 ColVIcre-Kif3a $\mathrm{f}^{f(f f x}$ mice, but none of the control animals, exhibited signs of dysplasia (Figure 4F). Moreover, ColVlcre-Kif3a $a^{f l / f l x}$ mice displayed an increased presence of $\mathrm{F} 4 / 80^{\text {positive }}$ macrophages in areas with crypt loss (Figure $4 \mathrm{G}$ ), whereas numbers of $\mathrm{Gr}-1^{\text {positive }}$ granulocytes, B220 $0^{\text {positive }} \mathrm{B}$ cells and CD $3^{\text {positive }} \mathrm{T}$ cells 
were unaltered (supplementary Figure 4). Consistent with the increased susceptibility of ColVIcre-Kif3 ${ }^{f l x / f l x}$ mice to DSS-induced colitis we detected decreased numbers of PC on colonic fibroblasts during acute colitis compared to those of untreated mice further underpinning a link between the presence of PC and intestinal inflammation (Figure 4G). Strikingly, we also detected decreased numbers of PC in regions of inflamed tissue from patients with ulcerative colitis, when compared to neighboring normal tissue (Figure 4I).

ColVIcre-IFT88 $8^{f l / f I x}$ mice display less colonic PC and increased susceptibility to DSS-induced colitis

Our analysis of ColVIcre-Kif3a $a^{f l x f l x}$ mice revealed a link between PC loss on colonic fibroblasts and susceptibility to DSS-induced colitis as well as AOM/DSS-induced carcinogenesis. To validate these observations, we generated a second mouse model for PC loss in colonic fibroblasts by crossing a conditional knockout allele of the intra-flagellar transport protein $88\left(I f t 88^{f f / f f x}\right)$ with ColVI-cre mice. Similar to Kif3A, Ift88 is essential for cilia assembly and absence of this protein leads to the loss of PC (Haycraft et al, 2007). As expected, ColVIcre-mediated deletion of IFT88 was only detectable in colonic fibroblasts but not epithelial cells (Supplementary Figure S5), resulting in decreased numbers of PC in $v^{\text {vimentin }}{ }^{+}$colonic cells (Figures $5 \mathrm{~A}$ ). ColVIcre-Ift8 $8^{\text {flxfflx }}$ mice were more susceptible to DSSinduced colitis compared to control animals, as manifested by elevated weight loss, decreased colon size and increased crypt loss (Figures 5B-D). Moreover, male ColVIcre-

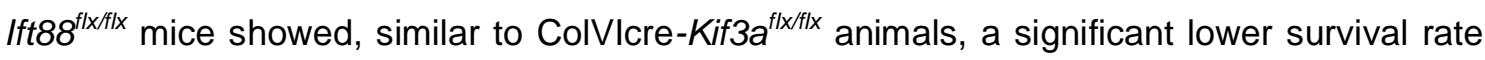
when exposed to the AOM/DSS colon carcinogenesis protocol (Figure 5E).

\section{Colons from DSS-treated PC-deficient mice exhibit an altered regenerative response}

We next looked into the molecular alterations associated with the elevated inflammatory response of the PC-deficient mouse strains. A critical role for the prototypic proinflammatory cytokine IL-6 in DSS-induced colitis is well established and indeed, we detected elevated IL-6 transcript levels in distal colons from DSS-treated ColVIcre-Kif3 ${ }^{f(x / f I x}$ mice as compared to controls (Supplementary Figure S6A). Macrophages can be important producers of IL-6 (Naito et al, 2004) and a higher number of $\mathrm{F} 4 / 80^{\text {positive }}$ macrophages in areas with crypt loss from DSS-treated ColVIcre-Kif3a ${ }^{f l x / x}$ mice showed detectable II-6 expression by IHC (Supplementary Figure S6B). In addition to macrophages, fibroblasts and epithelial cells can be significant producers of IL-6 (Waldner et al, 2012), and in DSS-treated ColVIcre-IFT88 $8^{f / x / f l}$ mice both displayed an elevated production of IL-6 as determined by immunofluorescent analysis of colons (Figure 6A). Targets of IL-6 are the transcription factors NFKB and STAT3, which can interact with each other and play an important role in 
linking inflammation and cancer (Karin \& Clevers, 2016)(Taniguchi \& Karin, 2018). A more frequent nuclear localization and thus activation of NFKB was detectable in colonic fibroblasts and epithelial cells of DSS-treated ColVIcre-IFT88 $8^{f / f / x}$ mice, whereas higher levels of nuclear phospho-STAT3 were only evident in vimentin ${ }^{+}$fibroblasts (Figures 6B,C). Strikingly, DSS-treated colons of ColVIcre-IFT88 $8^{f / x / f l x}$ animals showed significantly lower expression levels of the transcription factor HES1 (Figure 6D), an important downstream target of Notch signaling, a key pathway for the regeneration of intestinal epithelial cells during DSS-induced colitis (Okamoto et al, 2009). This finding concurs with the decreased transcript levels of Hes1 found in the distal region of colons from colitic ColVIcre-IFT88 $8^{f / x f f x}$ mice (Supplementary Figure S6A).

\section{Decreased numbers of PC in human CRC biopsies}

To investigate whether PC are also present in human colons we performed IHC analysis of three biopsies of healthy donors. Indeed, PC were detectable mostly on vimentin ${ }^{+}$ fibroblasts in the lamina propria and only on few epithelial cells (Figure 7A, Supplementary Figures S7A,B). We next analyzed the presence of PC on tumor tissues of $28 \mathrm{CRC}$ patients at different stages of disease. Sections of tumor tissues of all four stages harboured decreased numbers of $\mathrm{PC}$ on vimentin ${ }^{\text {positive }}$ colonic fibroblasts when compared to the respective peri-tumoral region as well as normal colon (Figure $7 \mathrm{~B}$ ). Of note, the tissue sections of the stage 4 samples did not contain adjacent normal tissue and were thus compared with the mean calculated from the analysis of peritumoral tissue of stage 1-3 patients. Moreover, we noted that vimentin ${ }^{\text {positive }}$ regions were enlarged in the tumoral as compared to the peritumoral regions of several samples. Hence, we analyzed PC expression in regions containing exclusively vimentin ${ }^{\text {positive }}$ cells to convey a more unbiased approach. Notably, the latter analysis confirmed the decreased number of PC in tumor as compared to peritumoral areas (Figure 7C). 


\section{Discussion}

Various reports associate PC with tumorigenesis, but their role in tumor development appears to vary between different types of tumors. Reduced numbers of PC have been described for breast and pancreatic cancer, as well as melanoma (reviewed in (Liu et al, 2018)(Eguether \& Hahne, 2018)), whereas PC were reported to be maintained in about half of the tested biopsies of medulloblastoma and basal cell carcinoma (BCC) patients (Han et al, 2009)(Wong et al, 2009). This dichotomy is underlined by the observation in mouse models that, depending on the nature of the initiating oncogenic event, cilia ablation facilitates or blocks medulloblastoma as well as BCC tumor formation (Han et al, 2009)(Wong et al, 2009).

Here, we report that numbers of PC decrease during colon carcinogenesis in mice. Intriguingly, this finding in mice concurs with the lower number of PC in tumor areas of stage 1-4 CRC patients, when compared to peritumoral regions as well as healthy controls. We initiated a multicenter study to confirm this finding on a larger cohort of CRC samples and to evaluate whether CMS subtype-specific PC patterns exist. In line, a recent report described a correlation between the frequency of colonic PC and disease outcome in CRC patients (Dvorak et al, 2016). The authors found a significantly longer overall survival of CRC patients with a higher frequency of PC in the colon, concurring with our observations in mice. Nevertheless, this study did not assess which cells in the colon do express PC.

We found that in murine as well as human colon, mostly vimentin ${ }^{\text {positive }}$ stromal cells carry PC, which are, however, detectable only on a part of those cells. To investigate consequences of PC loss in colonic fibroblasts, we crossed the two commonly used mouse strains to study PC, i.e. Kif3a ${ }^{f f / f f x}$ and $I f t 88^{f / x / f x}$, to ColVlcre-transgenic mice, targeting mesenchymal cells including subsets of colonic fibroblasts (Armaka et al, 2008)(Koliaraki et al, 2015). Accordingly, the number of PC was significantly lower in colons of both ColVIcre-

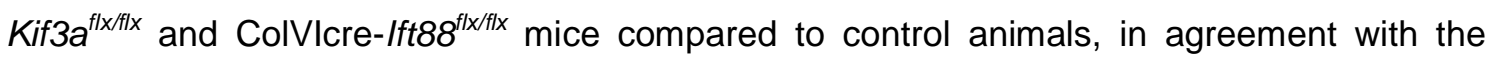
requirement of KIF3a and IFT88 for maintenance of PC. The decreased number of PC in the colon of these mice did not perturb the colonic architecture. This corroborates our previous observation in Tt/l3-deficient mice, in which the number of PC is similarly diminished without affecting colon architecture and homeostasis (Rocha et al, 2014).

It is well established that colonic fibroblasts cooperate with epithelial cells during colon carcinogenesis (Vermeulen et al, 2010). We studied the consequences of the loss of

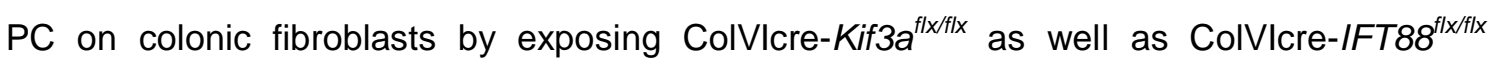
animals to chemically induced colitis-associated colon carcinogenesis (AOM/DSS model). Both mutant mouse strains displayed increased dysplasia suggesting that the partial loss of PC on colonic fibroblasts promotes tumorigenesis. In addition to their role in PC formation, 
KIF3a and IFT88 may promote cilia-independent functions, such as spindle orientation or mother centriole appendage formation (Kodani et al, 2013)(Delaval et al, 2011). Therefore, we decided to study both mutant mice deficient of PC to allow a conclusion whether a potential phenotype is truly cilia-dependent. The complementary results obtained in ColVIcreKif3a ${ }^{f(x f f l x}$ and ColVIcre-Ift8 $8^{f / x f f x}$ animals allow to conclude that decreased PC numbers are at their origin.

Interestingly, two recent articles described different roles for subsets of colonic fibroblast during CAC in mice (Pallangyo et al, 2015)(Koliaraki et al, 2015). In both studies, the role of IKK $\beta$ in CAC was investigated upon tissue-specific deletion in subsets of stromal cells in the colon using either colagenase1a2 (Col1a2)- or ColVI-Cre driven DNA recombination. In the former model tumor promotion was observed, while the latter resulted in decreased tumor formation. A likely explanation for these findings might be that the col1a2- and colVI-promoters target different stromal cell subsets, which may have distinct functions (Fordham \& Sansom, 2015). In fact, it appears that intestinal stromal cells consist of several subtypes that are not well defined yet (Roulis \& Flavell, 2016). In addition, it has been suggested that resting fibroblasts are capable to differentiate into distinct subsets that execute different functions (Kalluri, 2016). This is well illustrated by a recent report describing the presence of two different subsets, i.e. myofibroblasts and inflammatory fibroblasts, in pancreatic ductal adenocarcinoma (Öhlund et al, 2017).

We found that deficiency of PC on colonic fibroblasts renders ColVIcre-Kif3a $a^{f \mid x f l x}$ as well ColVIcre-Ift88 $8^{f / x / f x}$ mice more susceptible to DSS-induced colitis. Accordingly, decreased numbers of PC were detected in the colons of colitic mice. Moreover, the decreased number of PC detected in inflamed tissue areas of patients with ulcerative colitis corresponds with our observations in mice. Analysis of the distal parts of colons isolated from DSS-treated animals revealed elevated IL-6 transcript levels in ColVIcre-Kif3a $a^{f / x} / f x$ mice, which correlates with elevated numbers of macrophages that are well-established producers of IL-6 during inflammation in areas of crypt loss in mutant mice. Notably, in areas without crypt loss increased numbers of IL-6 expressing colonic fibroblasts were detectable in ColVIcreKif3 ${ }^{f f(x f l x}$ mice concurring with reports that colonic fibroblasts have the capacity to produce significant levels of IL-6 (Lin et al, 2013)(Koliaraki et al, 2015)(Shalapour \& Karin, 2015). The increased production of pro-inflammatory cytokines was linked to activation of NF-kb and Stat3 signaling in PC-deficient colonic fibroblasts derived from ColVIcre-Kif3a ${ }^{f / x / f \mid x}$ mice, in agreement with a report that reduced NF-kb signaling in ColVIcre targeted colonic fibroblasts dampens IL-6 production and thus inflammation in DSS-induced colitis (Koliaraki et al, 2015). Reports associating altered PC numbers with inflammation in vivo are still limited. A recent work from Reiter and colleagues describes that removal of PC on endothelial cells is 
dispensable for vascular development in mice (Dinsmore \& Reiter, 2016). Removal of endothelial PC, however, was found to promote atherosclerosis in mice that correlated with an increased expression of inflammatory genes including notably IL-6 and NF-kb (Dinsmore \& Reiter, 2016), thus concurring with our observations.

A concept is emerging that inflammation is an important driver in the regeneration of damaged tissue, by inducing hyperproliferation of epithelial tissue triggered by proinflammatory cytokines such as IL-6 (Kuhn et al, 2014)(Karin \& Clevers, 2016). Excessive production of pro-inflammatory cytokines, however, can also be deleterious and promote tumor formation (Todoric et al, 2016). In fact, we observed an increased incidence of dysplasia in DSS-treated ColVIcre-Kif3a $a^{f / x / f x}$ mice. DSS is not genotoxic, but intestinal inflammation was shown to induce DNA damage and thus promoting dysplasia (Westbrook et al, 2009). Therefore, the augmented inflammatory response in DSS-treated ColVIcreKif3 ${ }^{f|x| f \mid x}$ mice is most likely related to the observed incidence of dysplasia.

Several signaling pathways regulate the wound-healing process including NF-kB, and STAT3 (Karin \& Clevers, 2016). In addition, intact Notch signaling is required for the regenerative response of intestinal epithelia upon DSS-treatment (Okamoto et al, 2009)(Fazio \& Ricciardiello, 2016). Colonic epithelial cells in DSS-treated ColVIcre-Kif3a $a^{\text {flx/flx }}$ mice displayed significantly lower expression levels of the Notch target HES1, suggesting that impaired Notch signaling contributes to the disturbed wound healing process detected in these mice. Indeed, absent or very weak expression of HES1 was found in sessile serrated adenoma/polyp (SSA/p), a precursor lesion for colorectal carcinoma (Cui et al, 2016). Moreover, recent reports describe an inflammation and tumor-suppressive function of Notch/Hes1 signaling in the colonic epithelium of patients with ulcerative colitis or CRC, respectively (Wang et al, 2017)(Tsuchiya et al, 2017; Prossomariti et al, 2017).

Taken together, decreased numbers of PC on colonic fibroblasts in mice has no consequence in steady-state but enhances the inflammatory response in acute colitis and promotes chemically induced colon carcinogenesis. The observations made in mice concur with the corresponding human pathologies, i.e. colitis and CRC, as those display decreased numbers of PC on intestinal fibroblasts. 


\section{Material and Methods}

\section{Animal experimentation}

Mouse experiments were performed in strict accordance with the guidelines of the European Community (86/609/EEC) and the French National Committee (87/848) for care and use of laboratory animals. To study PC we used Kif3a $a^{f(x / f l x}$ and $I f t 88^{f / f f l x}$ mice which have been previously described (Marszalek et al, 1999)(Haycraft et al, 2007). Tissue specific knock-out mice were obtained by crossing with ColVIcre-transgenic strain. The latter was obtained by G. Kolias (Armaka et al, 2008)(Koliaraki et al, 2015). Mice were maintained on C57BL/6 genetic background, and experimental groups contained littermates that were caged together according to gender. Genotyping was done as described before (Marszalek et al, 1999)(Haycraft et al, 2007)(el Marjou et al, 2004)(Armaka et al, 2008). ColVIcre-Kif3a ${ }^{f l / f f l}$ and ColVIcre-Ift8 $8^{f(x / f l}$ mice were fertile, born at expected mendelian ratio and displayed no overt intestinal phenotype. Mice used for the experiments described were used at age of 8-12 weeks.

\section{Patient samples}

Formalin-fixed paraffin-embedded CRC samples of different grades were obtained from the institutional biobank of the University Hospital of Liege, Belgium following the approval of the Institutional Ethics Committee No. 2009/69. According to Belgian law, informed consent was not necessary because all patients are informed that their residual surgical material can be used for research unless they opt-out. Details of CRC samples obtained from the University Hospital ( $\mathrm{CHU}$ ) of Liège are listed in Appendix Table S1. The cohort of patients with ulcerative colitis from the Hospital Saint Antoine (Paris) was declared under the number \#CNIL1104603 and all patients (two men, 38 and 43 years old, and two women, 25 and 57 years old) gave consent to this research.

\section{Histology and immunohistochemistry}

Organs were fixed in formalin solution for $24 \mathrm{~h}$. Histological examination was performed on paraffin-embedded sections stained with hematoxylin and eosin. Immunohistochemistry was performed on formalin-fixed and paraffin-embedded tissues cut into 4- $\mu \mathrm{m}$ sections. After blocking of non-specific binding (with TBS-10\%goat serum-5\%BSA-5\%milk-0,3\%triton), samples were incubated with primary antibody (see Table 1 ) for $1 \mathrm{~h}$ at room temperature or overnight at $4^{\circ} \mathrm{C}$ and avidin/biotin or polymer horse radish peroxidase kits for primary mouse or rabbit antibodies (Vector Laboratories) were used for detection. For immunofluorescence analysis, samples were incubated with primary antibodies for $1 \mathrm{~h}$ and revealed with fluorescent-labeled secondary antibodies (Vector Laboratories). DNA was stained with $20 \mu \mathrm{g} / \mathrm{ml} \mathrm{4',6'-diamidino-2-phenylindole} \mathrm{(DAPI).} \mathrm{For} \mathrm{the} \mathrm{detection} \mathrm{of} \mathrm{PC} \mathrm{we} \mathrm{followed} \mathrm{a}$ 
previously described protocol that allows detection of PC on paraffin embedded tissue (Hassounah et al, 2013).

Table 1: Antibodies used in IHC on paraffin embedded tissues.

\begin{tabular}{|c|c|c|c|c|}
\hline antigen & company & clone/reference & concentration & dilution used \\
\hline Arl13b & Neuromab & N295B/6675-287 & $1 \mathrm{mg} / \mathrm{ml}$ & $1 / 1000$ \\
\hline Arl13b & proteintech & 17711-1-AP & $41 \mu \mathrm{g} / 150 \mu \mathrm{l}$ & $1 / 1000$ \\
\hline B220 & $\mathrm{BD}$ & 553086 & $0.5 \mathrm{mg} / \mathrm{ml}$ & $1 / 800$ \\
\hline BrdU & Biolegend & 339810 & $0.5 \mathrm{mg} / \mathrm{ml}$ & $1 / 100$ \\
\hline CD3 & Thermofisher & sp7/RM-9107 & $\begin{array}{l}\text { not provided } \\
\text { by supplier }\end{array}$ & $1 / 400$ \\
\hline CD140a & Cell signaling & D1E1E/3174 & $\begin{array}{l}\text { not provided } \\
\text { by supplier }\end{array}$ & $1 / 400$ \\
\hline E-cadherin & Cell signaling & 24E10/3195 & $\begin{array}{l}\text { not provided } \\
\text { by supplier }\end{array}$ & $1 / 500$ \\
\hline $\mathrm{F} 4 / 80$ & Hycult Biotech & BM8/HM1066 & $0.1 \mathrm{mg} / \mathrm{ml}$ & $1 / 800$ \\
\hline $\mathrm{F} 4 / 80$ & Cell Signalling & D2S9R & $\begin{array}{l}\text { not provided } \\
\text { by supplier }\end{array}$ & $1 / 250$ \\
\hline Gr-1 & Biolegend & RB6-8C5/108403 & $0.5 \mathrm{mg} / \mathrm{ml}$ & $1 / 100$ \\
\hline HES1 & Cell signaling & D6P2U & $\begin{array}{l}\text { not provided } \\
\text { by supplier }\end{array}$ & $1 / 1000$ \\
\hline IL-6 & Novus & IL6/1270 & $0,2 \mathrm{mg} / \mathrm{ml}$ & $1 / 100$ \\
\hline Ki-67 & Invitrogen & solA15 & $0,5 \mathrm{mg} / \mathrm{ml}$ & $1 / 1000$ \\
\hline p65 & Cell signaling & D14E12 & $\begin{array}{l}\text { not provided } \\
\text { by supplier }\end{array}$ & $1 / 500$ \\
\hline pStat3 & Cell signaling & D3A7 & $\begin{array}{l}\text { not provided } \\
\text { by supplier }\end{array}$ & $1 / 1000$ \\
\hline $\begin{array}{l}\text { gamma- } \\
\text { tubulin }\end{array}$ & Sigma & AK-15/T3320 & $8 \mathrm{mg} / \mathrm{ml}$ & $1 / 1000$ \\
\hline alphaSMA & Abcam & E184/32575 & $0.023 \mathrm{mg} / \mathrm{ml}$ & $1 / 500$ \\
\hline alphaSMA & ebioscience & $1 \mathrm{~A} 4 / 14-9760$ & $0.5 \mathrm{mg} / \mathrm{ml}$ & $1 / 500$ \\
\hline Vimentin & Cell signaling & $\mathrm{D} 21 \mathrm{H} 3 / 5741$ & $\begin{array}{l}\text { not provided } \\
\text { by supplier }\end{array}$ & $1 / 500$ \\
\hline Vimentin & biolegend & Poly29191 & $2 \mathrm{mg} / \mathrm{ml}$ & $1 / 500$ \\
\hline
\end{tabular}

DSS-induced colitis and colitis associated carcinogenesis (CAC)

To induce colitis, 8-12 week-old mice were treated for 7 days with $2.5 \%(\mathrm{w} / \mathrm{v})$ dextran sodium sulfate (DSS; TdB Sweden) added in the drinking water. Mice were sacrificed at indicated time points. The weight of the mice was daily followed and in case weight loss was more important than $20 \%$ mice were sacrificed.

For colitis-associated carcinogenesis, mice were intraperitoneally injected with azoxymethane (AOM), followed by three cycles of $2.5 \%(\mathrm{w} / \mathrm{v})$ DSS administered in the drinking water (Figure 2A). In between the cycles the mice received no treatment for 2 weeks. For histological analysis the entire colon was prepared according to the Swiss roll procedure, fixed with formaldehyde and embedded in paraffin. Four $\mu \mathrm{m}$ sections were 
stained with hematoxylin and eosin, Alcian blue or deparaffinized and subsequently incubated with the primary antibody described below. Histological grading of AOM/DSSinduced tumors was determined with blinded genotype according to the described classification of intestinal neoplasia (Washington et al, 2013).

\section{BrdU incorporation proliferation assay}

12-week-old mice were intraperitoneally injected with $100 \mu \mathrm{g}$ Bromodeoxyuridine (BrdU) per gram body weight. Colons were dissected $2 \mathrm{~h}$ or 5 days following injection. Proliferating cells were detected with anti-BrdU antibody (Biolegend), and $\mathrm{BrdU}^{+}$cells were quantified from at least three animals per condition.

\section{Cell culture}

Protocols for isolation of intestinal epithelial cells (IEC) and fibroblasts (InF) were modified according to Roulis et al. (Roulis et al, 2014). Briefly, colons were isolated from mice, flushed with PBS/2\% FCS, and then opened longitudinally and processed as follows. Intestinal pieces were cut into small pieces and incubated in IEC buffer (PBS/2\% FCS/1 mM EDTA/1 $\mathrm{mM} \mathrm{DTT}$ ) at $37^{\circ} \mathrm{C}$ for 45 minutes under continuous shaking to releases IEC. For the isolation of InF the colon was treated as described to separate IEC, washed, and further processed by treatment with $3 \mathrm{mg} / \mathrm{ml}$ Collagenase type I (Sigma) and $0.1 \mathrm{mg} / \mathrm{ml}$ Dispase (Dominique Dutscher SA, France) in DMEM for $30 \mathrm{~min}$ at $37^{\circ} \mathrm{C}$. Cells were filtered through a $70-\mu \mathrm{m}$ strainer, washed with PBS/2\% FCS and subsequently analyzed.

\section{Microscopy and imaging}

Histological slides were scanned using Nanozoomer 2.0 HT scanner with a 40x objective, and visualized with NDP.view2 viewing software (Hamamatsu). Fluorescent images were acquired on a brightfield microscope (Leica) using Metamorph software, inverted Confocal SP5 (Leica) using the Leica LAS AF software or an Andor Dragonfly Spinning Disk Confocal microscope employing Imaris software. Quantification of PC and Vimentin ${ }^{\text {positive }}$ fibroblasts was done on at least 5 random fields (about $1 \mathrm{~mm}^{2}$ each) per sample using Imaris and ImageJ softwares. Images were processed with ImageJ. Images were assembled and adjusted with Adobe Photoshop/ Illustrator. Counting of PC was performed using z-stack acquisition. Co-staining with cell markers was confirmed on distinct layers. In analyses of human biopsies PC numbers were calculated either per mm2 or per Vimentin-stained area using arbitrary unit ( $A U$ corresponding to 10000 square pixel) of vimentin ${ }^{\text {positive }}$ cells.

\section{$R T-P C R$ and $q R T-P C R$}

RNA was extracted from homogenized mouse organs or from cells using TRlzol reagent (Euromedex) following the standard protocol. RNA was translated to cDNA with Superscriptlll reverse transcriptase (Invitrogen) using Random Hexamers (Invitrogen). Quantitative RT-PCR was applied under standard conditions using SYBR Green (Roche) on 
a LightCycler 480 (Roche). The relative mRNA expression levels of each gene were expressed as the $\mathrm{N}$-fold difference in target gene expression relative to the TBP gene.

\section{Statistical analysis}

Statistical analysis was performed employing GraphPad Prism version 5. More precisely, we first validated normal distribution of values (using KS normality test, D'Agostino - Pearson omnibus normality test, Shapiro-Wilk normality test). Then, values of the different groups were analyzed by unpaired $t$ test if the variances of the groups were significantly different and unpaired t test with a Welch's correction if the variances were significantly different. If values were not normally distributed, a non-parametric Mann-Whitney test was used. 


\section{References}

Armaka M, Apostolaki M, Jacques P, Kontoyiannis DL, Elewaut D \& Kollias G (2008) Mesenchymal cell targeting by TNF as a common pathogenic principle in chronic inflammatory joint and intestinal diseases. J. Exp. Med. 205: 331-337

Beaugerie L, Carrat F, Nahon S, Zeitoun J-D, Sabate J-M, Peyrin-Biroulet L, Colombel J-F, Allez M, Fléjou J-F, Kirchgesner J, Svrcek M \& CESAME Study Group (2017) High risk of anal and rectal cancer in patients with anal and/or perianal Crohn's disease. Clin. Gastroenterol. Hepatol. Off. Clin. Pract. J. Am. Gastroenterol. Assoc. 16: 892-899

Becht E, de Reyniès A, Giraldo NA, Pilati C, Buttard B, Lacroix L, Selves J, Sautès-Fridman C, Laurent-Puig P \& Fridman WH (2016) Immune and Stromal Classification of Colorectal Cancer Is Associated with Molecular Subtypes and Relevant for Precision Immunotherapy. Clin. Cancer Res. Off. J. Am. Assoc. Cancer Res. 22: 4057-4066

Caspary T, Larkins CE \& Anderson KV (2007) The graded response to Sonic Hedgehog depends on cilia architecture. Dev. Cell 12: 767-778

Cui M, Awadallah A, Liu W, Zhou L \& Xin W (2016) Loss of Hes1 Differentiates Sessile Serrated Adenoma/polyp from Hyperplastic Polyp. Am. J. Surg. Pathol. 40: 113-119

Delaval B, Bright A, Lawson ND \& Doxsey S (2011) The cilia protein IFT88 is required for spindle orientation in mitosis. Nat. Cell Biol. 13: 461-468

Dinsmore C \& Reiter JF (2016) Endothelial primary cilia inhibit atherosclerosis. EMBO Rep. 17: 156-166

Dvorak J, Hadzi Nikolov D, Dusek L, Filipova A, Richter I, Buka D, Ryska A, Mokry J, Filip S, Melichar B, Buchler T \& Abrahamova J (2016) Prognostic significance of the frequency of primary cilia in cells of small bowel and colorectal adenocarcinoma. J. BUON Off. J. Balk. Union Oncol. 21: 1233-1241

Eguether T \& Hahne M Mixed signals from the cell's antennae: Primary cilia in cancer. EMBO Rep.: in press

Eichele DD \& Kharbanda KK (2017) Dextran sodium sulfate colitis murine model: An indispensable tool for advancing our understanding of inflammatory bowel diseases pathogenesis. World J. Gastroenterol. 23: 6016-6029

Fazio C \& Ricciardiello L (2016) Inflammation and Notch signaling: a crosstalk with opposite effects on tumorigenesis. Cell Death Dis. 7: e2515

Fordham RP \& Sansom OJ (2015) Colon contradictions: NF-KB signaling in intestinal tumorigenesis. J. Exp. Med. 212: 2185

Gerdes JM, Davis EE \& Katsanis N (2009) The vertebrate primary cilium in development, homeostasis, and disease. Cell 137: 32-45

Gradilone SA, Radtke BN, Bogert PS, Huang BQ, Gajdos GB \& LaRusso NF (2013) HDAC6 inhibition restores ciliary expression and decreases tumor growth. Cancer Res. 73: 22592270

Grivennikov S, Karin E, Terzic J, Mucida D, Yu G-Y, Vallabhapurapu S, Scheller J, RoseJohn S, Cheroutre H, Eckmann L \& Karin M (2009) IL-6 and Stat3 are required for survival of intestinal epithelial cells and development of colitis-associated cancer. Cancer Cell 15: 103-113

Guinney J, Dienstmann R, Wang X, de Reyniès A, Schlicker A, Soneson C, Marisa L, Roepman P, Nyamundanda G, Angelino P, Bot BM, Morris JS, Simon IM, Gerster S, Fessler E, De Sousa E Melo F, Missiaglia E, Ramay H, Barras D, Homicsko K, et al (2015) The consensus molecular subtypes of colorectal cancer. Nat. Med. 21: 1350-1356

Han Y-G, Kim HJ, Dlugosz AA, Ellison DW, Gilbertson RJ \& Alvarez-Buylla A (2009) Dual and opposing roles of primary cilia in medulloblastoma development. Nat. Med. 15: 10621065 
Hao XP, Lucero CM, Turkbey B, Bernardo ML, Morcock DR, Deleage C, Trubey CM, Smedley J, Klatt NR, Giavedoni LD, Kristoff J, Xu A, Del Prete GQ, Keele BF, Rao SS, Alvord WG, Choyke PL, Lifson JD, Brenchley JM, Apetrei C, et al (2015) Experimental colitis in SIV-uninfected rhesus macaques recapitulates important features of pathogenic SIV infection. Nat. Commun. 6: 8020

Hassounah NB, Nagle R, Saboda K, Roe DJ, Dalkin BL \& McDermott KM (2013) Primary cilia are lost in preinvasive and invasive prostate cancer. PloS One 8: e68521

Haycraft CJ, Zhang Q, Song B, Jackson WS, Detloff PJ, Serra R \& Yoder BK (2007) Intraflagellar transport is essential for endochondral bone formation. Dev. Camb. Engl. 134: 307-316

Kalluri R (2016) The biology and function of fibroblasts in cancer. Nat. Rev. Cancer 16: 582598

Karin M \& Clevers H (2016) Reparative inflammation takes charge of tissue regeneration. Nature 529: 307-315

Ko JY \& Park JH (2013) Mouse models of polycystic kidney disease induced by defects of ciliary proteins. BMB Rep. 46: 73-79

Kodani A, Salomé Sirerol-Piquer M, Seol A, Garcia-Verdugo JM \& Reiter JF (2013) Kif3a interacts with Dynactin subunit p150 Glued to organize centriole subdistal appendages. EMBO J. 32: 597-607

Koliaraki V, Pasparakis M \& Kollias G (2015) IKK $\beta$ in intestinal mesenchymal cells promotes initiation of colitis-associated cancer. J. Exp. Med. 212: 2235-2251

Kuhn KA, Manieri NA, Liu T-C \& Stappenbeck TS (2014) IL-6 stimulates intestinal epithelial proliferation and repair after injury. PloS One 9: e114195

Kurahashi M, Nakano Y, Peri LE, Townsend JB, Ward SM \& Sanders KM (2013) A novel population of subepithelial platelet-derived growth factor receptor a-positive cells in the mouse and human colon. Am. J. Physiol. Gastrointest. Liver Physiol. 304: G823-834

Lee SM, Kim N, Son HJ, Park JH, Nam RH, Ham MH, Choi D, Sohn SH, Shin E, Hwang Y-J, Sung J, Lee DH \& Lee H-N (2016) The Effect of Sex on the Azoxymethane/Dextran Sulfate Sodium-treated Mice Model of Colon Cancer. J. Cancer Prev. 21: 271-278

Lin J-T, Wang J-Y, Chen M-K, Chen H-C, Chang T-H, Su B-W \& Chang P-J (2013) Colon cancer mesenchymal stem cells modulate the tumorigenicity of colon cancer through interleukin 6. Exp. Cell Res. 319: 2216-2229

Liu H, Kiseleva AA \& Golemis EA (2018) Ciliary signalling in cancer. Nat. Rev. Cancer 18:

Malvezzi M, Carioli G, Bertuccio P, Boffetta P, Levi F, La Vecchia C \& Negri E (2018) European cancer mortality predictions for the year 2018 with focus on colorectal cancer. Ann. Oncol. Off. J. Eur. Soc. Med. Oncol. 29: 1016-1022

Marszalek JR, Ruiz-Lozano P, Roberts E, Chien KR \& Goldstein LS (1999) Situs inversus and embryonic ciliary morphogenesis defects in mouse mutants lacking the KIF3A subunit of kinesin-II. Proc. Natl. Acad. Sci. U. S. A. 96: 5043-5048

Minoo P, Zlobec I, Peterson M, Terracciano L \& Lugli A (2010) Characterization of rectal, proximal and distal colon cancers based on clinicopathological, molecular and protein profiles. Int. J. Oncol. 37: 707-718

Naito Y, Takagi T, Uchiyama K, Kuroda M, Kokura S, Ichikawa H, Yanagisawa R, Inoue K-I, Takano H, Satoh M, Yoshida N, Okanoue T \& Yoshikawa T (2004) Reduced intestinal inflammation induced by dextran sodium sulfate in interleukin-6-deficient mice. Int. J. Mol. Med. 14: 191-196

Öhlund D, Handly-Santana A, Biffi G, Elyada E, Almeida AS, Ponz-Sarvise M, Corbo V, Oni TE, Hearn SA, Lee EJ, Chio IIC, Hwang C-I, Tiriac H, Baker LA, Engle DD, Feig C, Kultti A, Egeblad M, Fearon DT, Crawford JM, et al (2017) Distinct populations of inflammatory fibroblasts and myofibroblasts in pancreatic cancer. J. Exp. Med. 214: 579-596 
Okamoto R, Tsuchiya K, Nemoto Y, Akiyama J, Nakamura T, Kanai T \& Watanabe M (2009) Requirement of Notch activation during regeneration of the intestinal epithelia. Am. J. Physiol. Gastrointest. Liver Physiol. 296: G23-35

Pallangyo CK, Ziegler PK \& Greten FR (2015) IKK $\beta$ acts as a tumor suppressor in cancerassociated fibroblasts during intestinal tumorigenesis. J. Exp. Med. 212: 2253-2266

Prossomariti A, Scaioli E, Piazzi G, Fazio C, Bellanova M, Biagi E, Candela M, Brigidi P, Consolandi C, Balbi T, Chieco P, Munarini A, Pariali M, Minguzzi M, Bazzoli F, Belluzzi A \& Ricciardiello L (2017) Short-term treatment with eicosapentaenoic acid improves inflammation and affects colonic differentiation markers and microbiota in patients with ulcerative colitis. Sci. Rep. 7: 7458

Rocha C, Papon L, Cacheux W, Marques Sousa P, Lascano V, Tort O, Giordano T, Vacher S, Lemmers B, Mariani P, Meseure D, Medema JP, Bièche I, Hahne M \& Janke C (2014) Tubulin glycylases are required for primary cilia, control of cell proliferation and tumor development in colon. EMBO J. 33: 2247-2260

Roulis M \& Flavell RA (2016) Fibroblasts and myofibroblasts of the intestinal lamina propria in physiology and disease. Differ. Res. Biol. Divers. 92: 116-131

Roulis M, Nikolaou C, Kotsaki E, Kaffe E, Karagianni N, Koliaraki V, Salpea K, Ragoussis J, Aidinis V, Martini E, Becker C, Herschman HR, Vetrano S, Danese S \& Kollias G (2014) Intestinal myofibroblast-specific Tpl2-Cox-2-PGE2 pathway links innate sensing to epithelial homeostasis. Proc. Natl. Acad. Sci. U. S. A. 111: E4658-4667

Shalapour S \& Karin M (2015) Immunity, inflammation, and cancer: an eternal fight between good and evil. J. Clin. Invest. 125: 3347-3355

Suzuki R, Kohno H, Sugie S \& Tanaka T (2004) Sequential observations on the occurrence of preneoplastic and neoplastic lesions in mouse colon treated with azoxymethane and dextran sodium sulfate. Cancer Sci. 95: 721-727

Tanaka T, Kohno H, Suzuki R, Yamada Y, Sugie S \& Mori H (2003) A novel inflammationrelated mouse colon carcinogenesis model induced by azoxymethane and dextran sodium sulfate. Cancer Sci. 94: 965-973

Taniguchi K \& Karin M (2018) NF-KB, inflammation, immunity and cancer: coming of age. Nat. Rev. Immunol. 18: 309-324

Todoric J, Antonucci L \& Karin M (2016) Targeting Inflammation in Cancer Prevention and Therapy. Cancer Prev. Res. Phila. Pa 9: 895-905

Tsuchiya K, Hayashi R, Fukushima K, Hibiya S, Horita N, Negi M, Itoh E, Akashi T, Eishi Y, Motoya S, Takeuchi Y, Kunisaki R, Fukunaga K, Nakamura S, Yoshimura N, Takazoe M, lizuka B, Suzuki Y, Nagahori M \& Watanabe M (2017) Caudal type homeobox 2 expression induced by leukocytapheresis might be associated with mucosal healing in ulcerative colitis. J. Gastroenterol. Hepatol. 32: 1032-1039

Vermeulen L, De Sousa E Melo F, van der Heijden M, Cameron K, de Jong JH, Borovski T, Tuynman JB, Todaro M, Merz C, Rodermond H, Sprick MR, Kemper K, Richel DJ, Stassi G \& Medema JP (2010) Wnt activity defines colon cancer stem cells and is regulated by the microenvironment. Nat. Cell Biol. 12: 468-476

Waldner MJ, Foersch S \& Neurath MF (2012) Interleukin-6--a key regulator of colorectal cancer development. Int. J. Biol. Sci. 8: 1248-1253

Wang Y, Huang D, Chen K-Y, Cui M, Wang W, Huang X, Awadellah A, Li Q, Friedman A, Xin WW, Di Martino L, Cominelli F, Miron A, Chan R, Fox JG, Xu Y, Shen X, Kalady MF, Markowitz S, Maillard I, et al (2017) Fucosylation Deficiency in Mice Leads to Colitis and Adenocarcinoma. Gastroenterology 152: 193-205.e10

Washington MK, Powell AE, Sullivan R, Sundberg JP, Wright N, Coffey RJ \& Dove WF (2013) Pathology of rodent models of intestinal cancer: progress report and recommendations. Gastroenterology 144: 705-717 
Westbrook AM, Wei B, Braun J \& Schiestl RH (2009) Intestinal mucosal inflammation leads to systemic genotoxicity in mice. Cancer Res. 69: 4827-4834

Wirtz S, Neufert C, Weigmann B \& Neurath MF (2007) Chemically induced mouse models of intestinal inflammation. Nat. Protoc. 2: 541-546

Wloga D, Joachimiak E, Louka P \& Gaertig J (2017) Posttranslational Modifications of Tubulin and Cilia. Cold Spring Harb. Perspect. Biol. 9:

Wong SY, Seol AD, So P-L, Ermilov AN, Bichakjian CK, Epstein EH, Dlugosz AA \& Reiter JF (2009) Primary cilia can both mediate and suppress Hedgehog pathway-dependent tumorigenesis. Nat. Med. 15: 1055-1061 


\section{Acknowledgments:}

We are grateful to the excellent platforms in Montpellier, i.e. RIO imaging platform, the histology and animal experimentation platforms RHEM and RAM, as well as the IGMM mouse facility. Many thanks to Thierry Gostan and the platform SERANAD for help on the statistical analysis and Prof. BE Clausen for carefully reading the manuscript. This work was supported by INCA (project 2014-215) to MH and CJ, and by the SFNGE (Grant FARE) to MS and TE. Authors are thankful to Dr. Stephanie Gofflot, Biobank CHU Liege for providing clinical information.

\section{Author's contribution:}

$R T, C P, R L, T E, H T, J B, C M, S P$ conducting experiments, acquiring data and analyzing data. AT, MS, PS, VC, PD, CJ, MP, BL, VP, CJ, VP, MH: designing research studies and analyzing data.

$\mathrm{MH}$ : writing manuscript. 


\section{Figure legends}

Figure 1. Primary cilia in the colon are mostly present on stromal cells

(A-D) PC were identified by immunostaining for Arl13b (in green except in (D); arrowheads in the panel on the right-hand side), and in parallel by identifying epithelial cells with $\mathrm{E}$ cadherin(A), fibroblasts with vimentin (B) and CD140a (C), labeling (all in red), and myofibroblasts by a-SMA stain (D) in green). Nuclei were stained with DAPI (in blue). Scale bars represent 30,10 and $3 \mu \mathrm{m}$, respectively (from the left to the right).

Figure 2. Number of colonic primary cilia decreases during colon carcinogenesis.

(A) Experimental timeline for azoxymethane (AOM)/dextran sodium sulfate (DSS)-induced CAC.

(B) $\mathrm{HE}$ and corresponding confocal images (maximum projection) of paraffin-sections from colons of $A O M / D S S$ treated mice as indicated in (A). A representative example for a normal region and an area with high grade dysplasia are shown. Sections were stained with DAPI (blue) and an anti-Arl13b antibody (green) that specifically labels PC (arrowheads). Colonic fibroblasts were revealed with an anti-vimentin antibody (red). Scale bars represent $100 \mu \mathrm{m}$ in the panels in the middle and on the left side and $20 \mu \mathrm{m}$ in the panel on the right side. The panel on the right side includes 2,5x blow-ups.

(C) Box-and-whisker plots showing quantitative analysis of PC expression on vimentin ${ }^{+}$cells in normal colon, and colon with low and high grade dysplasia in mice exposed to the AOM/DSS protocol (analyzing at least 12 fields depicted from 4 different mice as illustrated in middle panel of (B)). Significance values were determined by two-tailed unpaired t-tests $\left({ }^{* * *} p<10^{-4}\right)$.

Figure 3. Decreased number of primary cilia in colonic fibroblasts promotes CAC

$(A, B)$ No alterations in the architecture between colons of $K i f 3 a^{f / x f f x}(A)$ and ColVIcre-Kif3a $a^{f(x / f \mid x}$

(B) mice are detectable. Representative images for stains with hematoxylin eosin, alcian blue and periodic acid-Schiff (PAS), as well as immunostain for the proliferation marker $\mathrm{Ki}-67$ are shown. Alcian blue stains negatively charged mucins, whereas PAS recognizes neutral mucins as well. Scale bars represent $100 \mu \mathrm{m}$

$(C, D)$ Quantitative analysis of PC expression on vimentin ${ }^{+}(C)$ and CD140a $^{+}(D)$ cells in colons of Kif3 $a^{f(x f f x}$ and ColVIcre-Kif3a $a^{f / x f f x}$ mice as described in Figure 2C.

$(\mathrm{E}, \mathrm{F}, \mathrm{G}) \mathrm{CAC}$ was induced in control $(n=7)$ and ColVIcre-Kif3a ${ }^{f(f / f \mid x}(n=7)$ female mice according to the timeline shown in Figure 2A.

(E) Representative images of hematoxylin and eosin staining of paraffin-embedded colon sections prepared as "Swiss roll". High dysplasia lesions are delimited by black lines.

$(F, G)$ Box-and-whisker plots depicting area of low $(F)$ and high grade $(G)$ dysplasia per mouse with a line indicating the median values.

(H) Kaplan-Meier survival curves of AOM/DSS-treated male Kif3a ${ }^{f \mid x f f l x}(n=13)$ and ColVIcreKif3a ${ }^{f f(x / f x}(n=11)$ mice. CAC was induced as described for Figure $2 A$.

$(C, D, G){ }^{* *} p<0.01,{ }^{* * * *} p<10^{-4}$ by two-tailed unpaired t-test.

Figure 4. ColVIcre-Kif3a $a^{f l x f l x}$ mice are more susceptible to DSS-induced colitis

(A) Experimental timeline for DSS-induced colitis in control $(n=6)$ and ColVIcre-Kif3a $a^{f / x} f f x$ $(n=6)$ male mice.

(B) Weight development in DSS-treated mice. ${ }^{*} p<0.05$ by two-tailed unpaired t-tests.

$(C, D, E)$ At the end of the protocol described in $(A)$ mice were sacrificed and colons were analyzed by histology for colitis severity including areas of crypt loss $(C, D)$ and architectural irregularities $(\mathrm{C}, \mathrm{E})$. Data are presented as Box-and-whisker plots. ${ }^{*} \mathrm{p}<0.05$ by two-tailed unpaired t-test.

(F) Incidence of dysplasia in DSS-treated ColVIcre-Kif3a ${ }^{\text {flxfflx }}$ mice. A representative image of a region with dysplasia is shown (circled area with a region of high grade dysplasia on 
the left, and low grade dysplasia on the right side), as well as the incidence of low and high grade dysplasia in ColVIcre-Kif3a $a^{f / x}$ flx and control mice.

(G) Elevated numbers of $\mathrm{F} 4 / 80^{+}$macrophages in colons of DSS-treated ColVIcre-Kif3a $a^{f / x f l x}$ mice. Representative images for F4/80 staining in areas with crypt loss are shown. At least 5 fields in the regions of crypt loss were analyzed from each colon of control $(n=6)$ and ColVIcre-Kif3a $a^{f \mid x f l x}(n=6)$ mice. Mean cell numbers were scored as low $(<500$ cells $\left./ \mathrm{mm}^{2}\right)$ or high $\left(>500\right.$ cells $\left./ \mathrm{mm}^{2}\right)$. Scale bar represent $250 \mu \mathrm{m}$.

$(\mathrm{H})$ Comparison of primary cilia numbers on vimentin ${ }^{\text {positive }}$ cells in colons of untreated and DSS-treated wild type mice. DSS-treatment was performed as illustrated in Figure 4A. Primary cilia in DSS-treated mice were depicted in areas of regeneration (14 fields of in average $\left.0.250 \mathrm{~mm}^{2}\right)$. Significance values were determined by two-tailed unpaired t-tests $\left({ }^{* * *}=\mathrm{p}<10^{-4}\right)$.

(I) Decreased number of PC in inflamed tissue of patients with ulcerative colitis. Shown are the results of matched-pair analysis for PC expression per vimentin ${ }^{+}$cells as arbitrary unit (AU, see material and methods). The lines link values obtained for regions of ulceration in the ileum with those of normal regions from the same patient, demonstrating the difference in each pair. ${ }^{*} p<0.05$ by paired t-test

Figure 5. Decreased numbers of colonic primary cilia in ColVIcre-Ift88 $8^{f / x / f l}$ mice increases the susceptibility to DSS-induced colitis and CAC.

(A) Quantitative analysis of PC expression on vimentin ${ }^{+}$cells in normal colon of $1 \mathrm{ft} 88^{f f x} / \mathrm{fl} x$ $(n=7)$ and ColVIcre-IFT88 ${ }^{f / x f f x}(n=6)$ mice. ${ }^{*} p<0.05$ by two-tailed unpaired t-test.

(B) Weight development in DSS-treated ColVIcre-Ift88 ${ }^{\text {fl/fflx }}(n=6)$ and control $(n=7)$ mice following the indicated timeline.

$(C, D)$ At the end of the protocol described in (B) mice were sacrificed and colons were analyzed for length $(C)$, and crypt loss (D). Data are presented as Box-and-whisker plots. ${ }^{*} \mathrm{p}<0,05$ by two-tailed unpaired $\mathrm{t}$-test.

(E) Kaplan-Meier survival curves of AOM/DSS-treated male Ift88 $8^{f / x f l x}(\mathrm{n}=11)$ and ColVIcreIft8 $^{f(x / f \mid x}(n=12)$ mice. Colon carcinogenesis was induced as described in Figure 2A.

Figure 6. Colons from DSS-treated ColVIcre-IFT88 $8^{f \mid x f f x}$ display an altered regenerative response

$(A, B, C, D)$ Representative images and corresponding quantification of vimentin ${ }^{\text {positive }}$ fibroblasts (in green) and vimentin ${ }^{\text {negative }}$ epithelial cells (identified by histological criteria) labeled for IL-6 (A), p65 (B), pSTAT3 (C) and HES1 (D) (all in red) in colons of Ift88 $8^{f x / f l x}$ and ColVIcre-Ift88 fixftx mice treated with DSS as described in Figure 4A. White arrow heads indicate IL-6 (A), nuclear staining for p65 (B), pSTAT3 (C) and HES1 (D) for fibroblasts, blue arrow heads the respective labeling for epithelial cells. Nuclei were stained with DAPI (in blue). Scale bars represent $100 \mu \mathrm{m}$. ${ }^{*} p<0.05$; ${ }^{* * \star *} p<10^{-4}$ was calculated by chi-squared test on absolute numbers and is presented as \% of cells positive for the indicated marker within vimentin ${ }^{\text {positive }}$ and epithelial cells, respectively.

Figure 7. Decreased number of primary cilia in tumoral tissues of CRC patients compared to peritumoral regions.

(A) Representative image of vimentin ${ }^{+}$fibroblasts (in green) expressing PC (identified using Arl13b, in red) in a normal colon. Nuclei were stained with DAPI (in blue). Most PC are detected on vimentin ${ }^{+}$cells (arrow), and few on vimentin-negative epithelial cells (arrow head). Scale bars represent $50 \mu \mathrm{m}$ in the upper and $10 \mu \mathrm{m}$ in the lower panel.

$(B, C)$ Quantitative analysis of PC presence on tumoral and peri-tumoral regions of colons from CRC patients $(n=28)$ at tumor $(T)$ stages 1 to 4 . The panels represent quantification of $P C$ expression (B) of vimentin positive cells per $\mathrm{mm}^{2}$ and $(C)$ per vimentin ${ }^{\text {positive }}$ cells as arbitrary unit ( $\mathrm{AU}$, see material and methods). Data are presented as Box-and-whisker plots. ${ }^{*} p<0,05,{ }^{* *} p<0,01,{ }^{* * * *} p<10^{-4}$ by two-tailed unpaired t-test. Images were acquired on an Andor Dragonfly Spinning Disk Confocal microscope and analyzed with the Imaris 
software. Quantification of PC and Vimentin ${ }^{+}$fibroblasts was done on at least 5 random fields (about $1 \mathrm{~mm}^{2}$ each) per sample using ImageJ software.

Supplementary Figure 1. Primary cilia are expressed by few E-cadherin ${ }^{+}$colonic epithelial cells.

Co-staining was performed for E-cadherin (red) and for primary cilia with Arl13b (arrowhead). Different z-stack slices are shown to validate the co-expression of Arl13b and E-cadherin (slices 13-19 represent $1.2 \mu \mathrm{m}$ thickness). Nuclei were stained with DAPI (in blue). Scale bar represent $10 \mu \mathrm{m}$.

\section{Supplementary Figure 2}

(A) Genotyping of ColVIcre-Kif3a $a^{f l / f l x}$ mice displaying Kif3a-depletion (ko) in the floxed (flx) alleles in the genomic DNA of total colon and colonic fibroblasts, but not colonic epithelial cells.

(B) Quantitative analysis of primary cilia expression on CD140+ cells in the distal, transverse and proximal regions (illustrated by the image on the right hand side) of normal colon of Kif3a ${ }^{f(x / f l x}$ and ColVIcre-Kif3a $a^{f / x f f x}$ mice as described for Figures $3 C$ and $D .{ }^{* * * *} \mathrm{p}<10^{-4}$ by two-tailed unpaired t-test.

\section{Supplementary Figure 3}

Relative weight of control $(n=7)$ and ColVIcre-Kif3a $a^{f l x f f x}(n=7)$ female mice exposed to the AOM/DSS protocol as described in Figure $2 A .{ }^{*} p<0.05,{ }^{* *} p<0.01$ by two-tailed unpaired t-test at indicated time points.

\section{Supplementary Figure 4}

Numbers of $\mathrm{Gr}^{+}$granulocytes, B220 ${ }^{+} \mathrm{B}$ cells and $\mathrm{CD}^{+} \mathrm{T}$ cells are similar in colons of DSStreated ColVIcre-Kif3a $a^{f / x / f x}$ mice (see Figure 4A). Representative images are shown. At least 5 fields in the regions of crypt loss were analyzed from each colon of control $(n=6)$ and ColVIcre-Kif3a $a^{f / x f l x}(n=6)$ mice. Mean cell numbers were scored as low $(<500$ cells $/ \mathrm{mm}^{2}$ ) or high $\left(>500\right.$ cells $\left./ \mathrm{mm}^{2}\right)$. Scale bar represents $250 \mu \mathrm{m}$.

\section{Supplementary Figure 5}

Genotyping of ColVIcre-Ift88 $8^{f \mid x f f x}$ mice showing Ift88-depletion (ko) in the floxed (flx) alleles in the genomic DNA of colonic fibroblasts, but not colonic epithelial cells.

\section{Supplementary Figure 6}

Elevated production of IL- 6 in colons from DSS-treated ColVIcre-Ift88 $8^{f \mid x f f x}$

(A) Transcript levels of II-6 and Hes1 in DSS treated Kif3a $a^{f(x / f x}$ and ColVlcre-Kif3a $a^{f(x / f l x}$ mice (according to the protocol shown in Figure 5B). Three independent mRNA samples were analyzed by qRT-PCR, and mean values standardized to expression of the house keeping gene Tbp are shown. Error bars represent SEM.

(B) Elevated numbers of IL-6-expressing $\mathrm{F} 4 / 80^{+}$macrophages in ColVIcre-Kif3a ${ }^{\text {ffx } f f l x}$ mice treated with DSS as described in Figure 4. At least 5 fields in the regions of crypt loss were analyzed. Scale bar represent $100 \mu \mathrm{m}$. ${ }^{*} p<0,05$ was calculated by chi-squared test.

\section{Supplementary Figure 7}

Representative images of the tissue of a stage I CRC patient showing decreased number of primary cilia in tumoral (A) versus peritumoral (B) tissues. PC are indicated by arrows in vimentin-positive fibroblasts, arrow head in epithelial cells and stars in endothelial cells with elongated nucleus. Scale bars represent $50 \mu \mathrm{m}$ and $10 \mu \mathrm{m}$ in the upper and lower panel respectively. 
bioRxiv preprint doi: https://doi.org/10.1101/2019.12.20.871772; this version posted December 29, 2019. The copyright holder for this preprint (which was not certified by peer review) is the author/funder. All rights reserved. No reuse allowed without permission. 
Table S1. CRC patients Characteristics $(n=28)$

\begin{tabular}{lc}
\hline Variable & Value $(\%)$ \\
\hline Age at diagnosis (yr) & \\
Median & 66 \\
Range & $42-82$ \\
Gender & \\
Male & $13(46.4)$ \\
Female & $15(53.6)$ \\
Tumor Location & \\
Colon & $26(92.9)$ \\
ascendant & $15(53.6)$ \\
transverse & $2(7.1)$ \\
descendent & $2(7.1)$ \\
sigmoid & $7(25)$ \\
Rectosigmoid & $2(7.1)$ \\
Tumor Stage & \\
I & $6(21.4)$ \\
II & $6(21.4)$ \\
III & $8(28.6)$ \\
IV & $8(28.6)$ \\
Metastasis (when data available) & \\
yes & $6(21.4)$ \\
no & $16(54.1)$ \\
& \\
\hline
\end{tabular}


Figure 1

A DAPI E-cadherin Arl13b 2 DAPI E-cadherin Arl13b
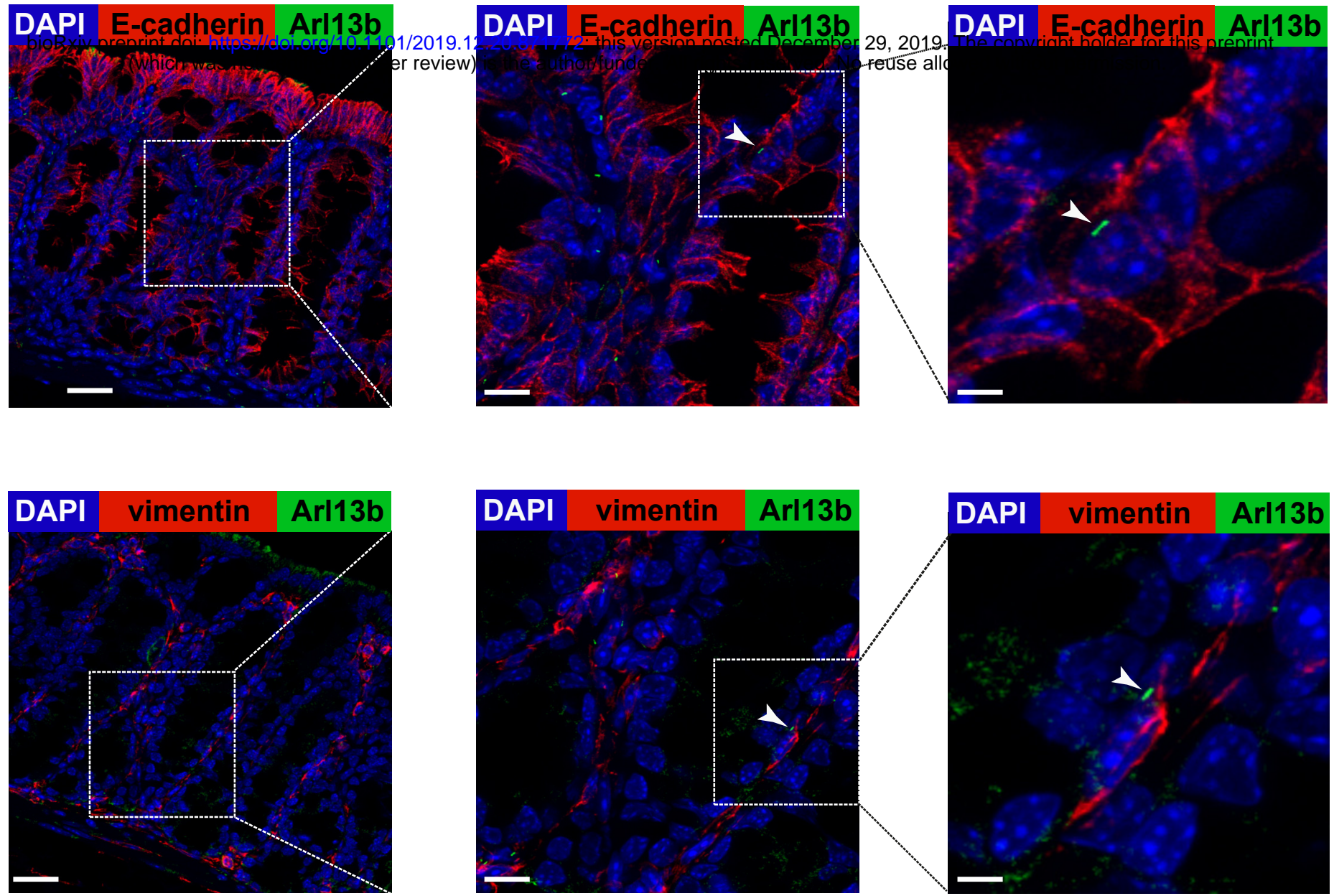

C
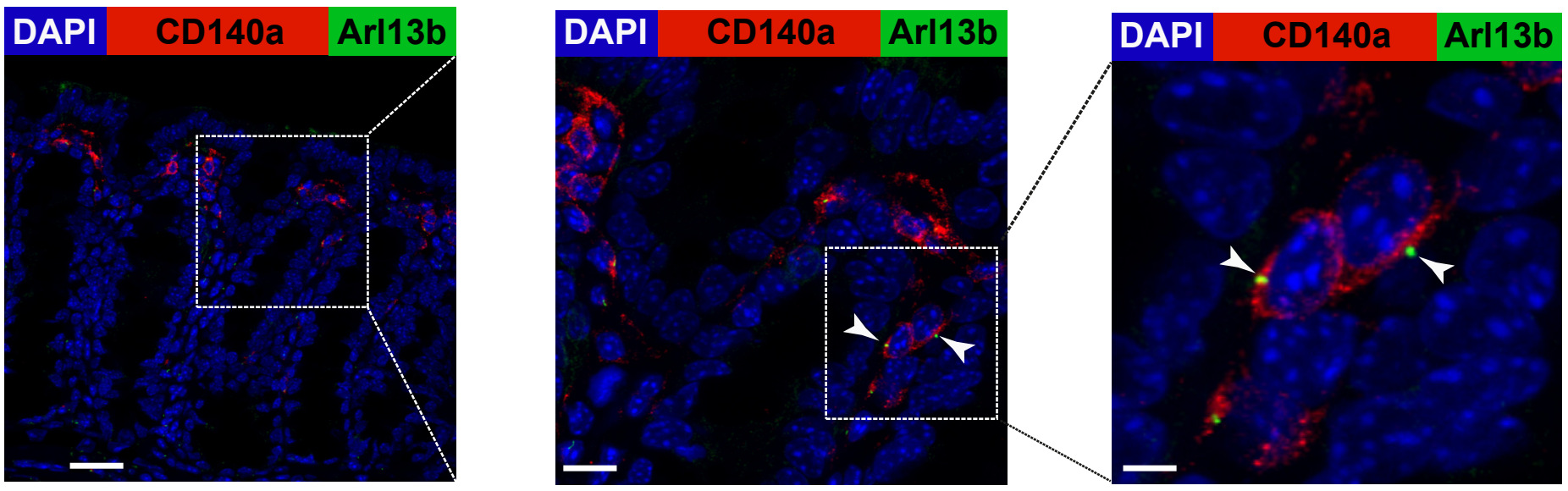

D

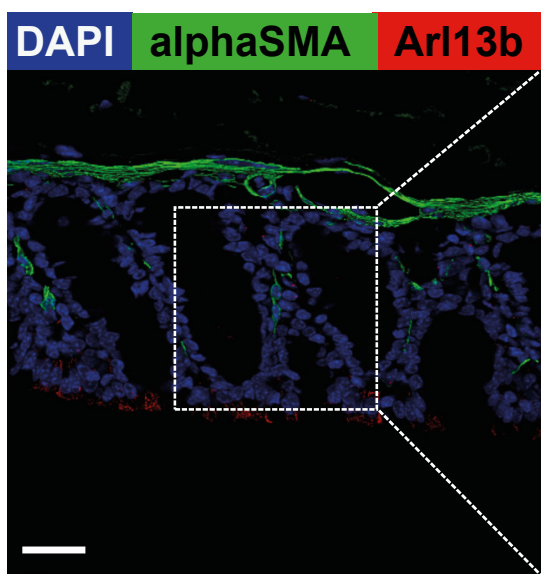

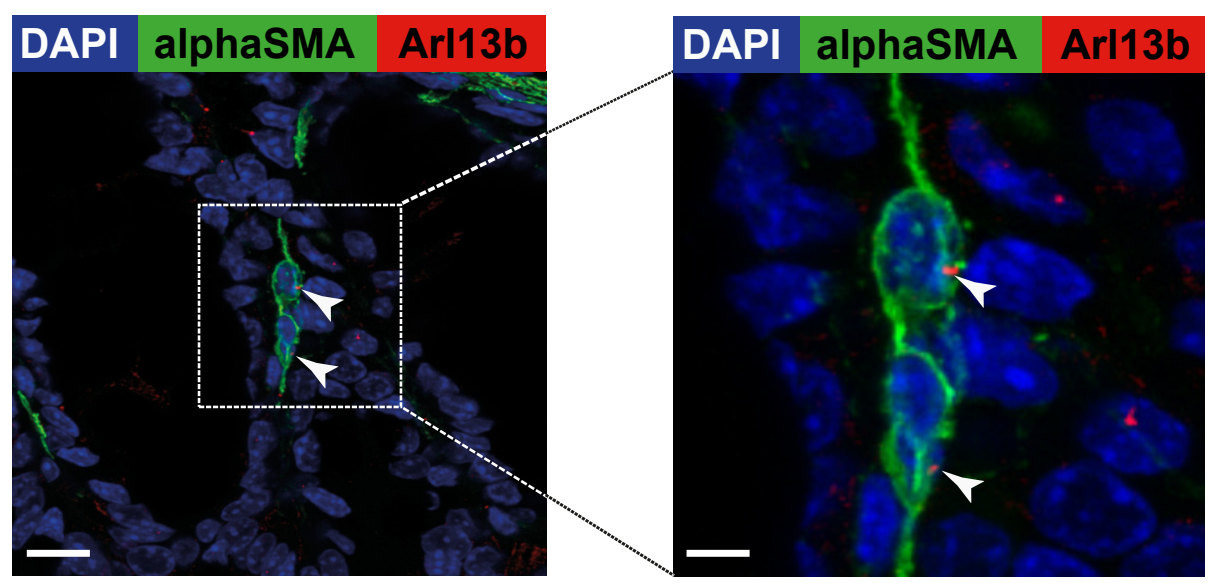


Figure 2

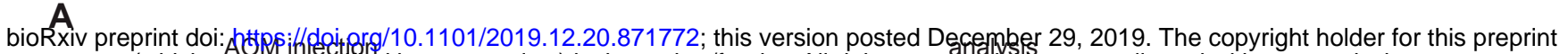
(which was ngt certified by peer review) is the author/funder. All rights reserved. No reuse allowed without permission.

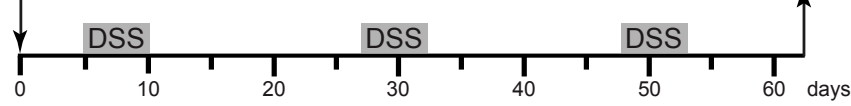

B
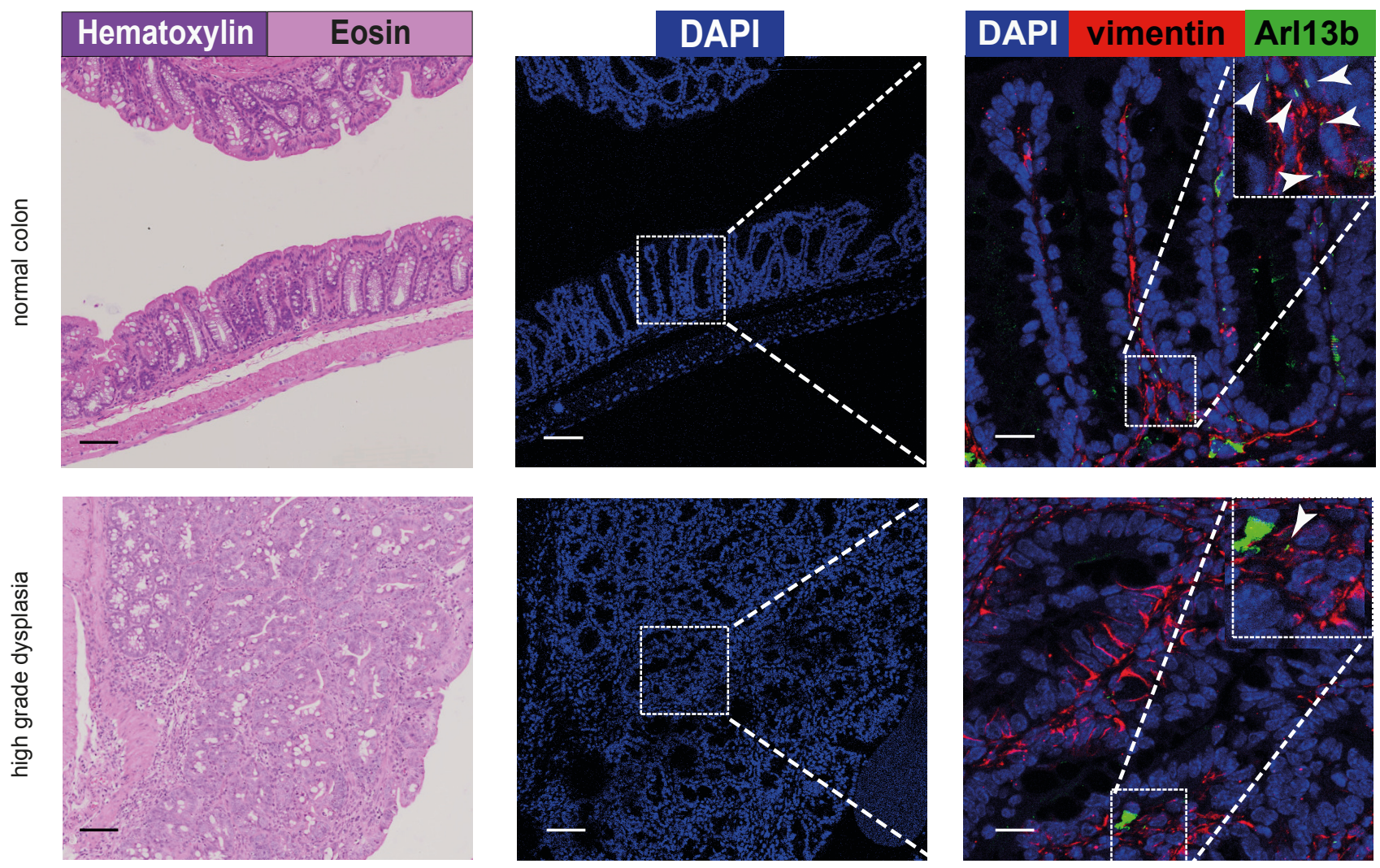

C

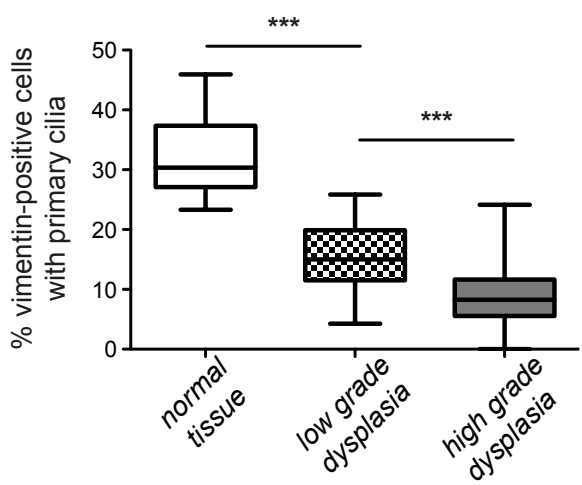




\section{Figure 3}

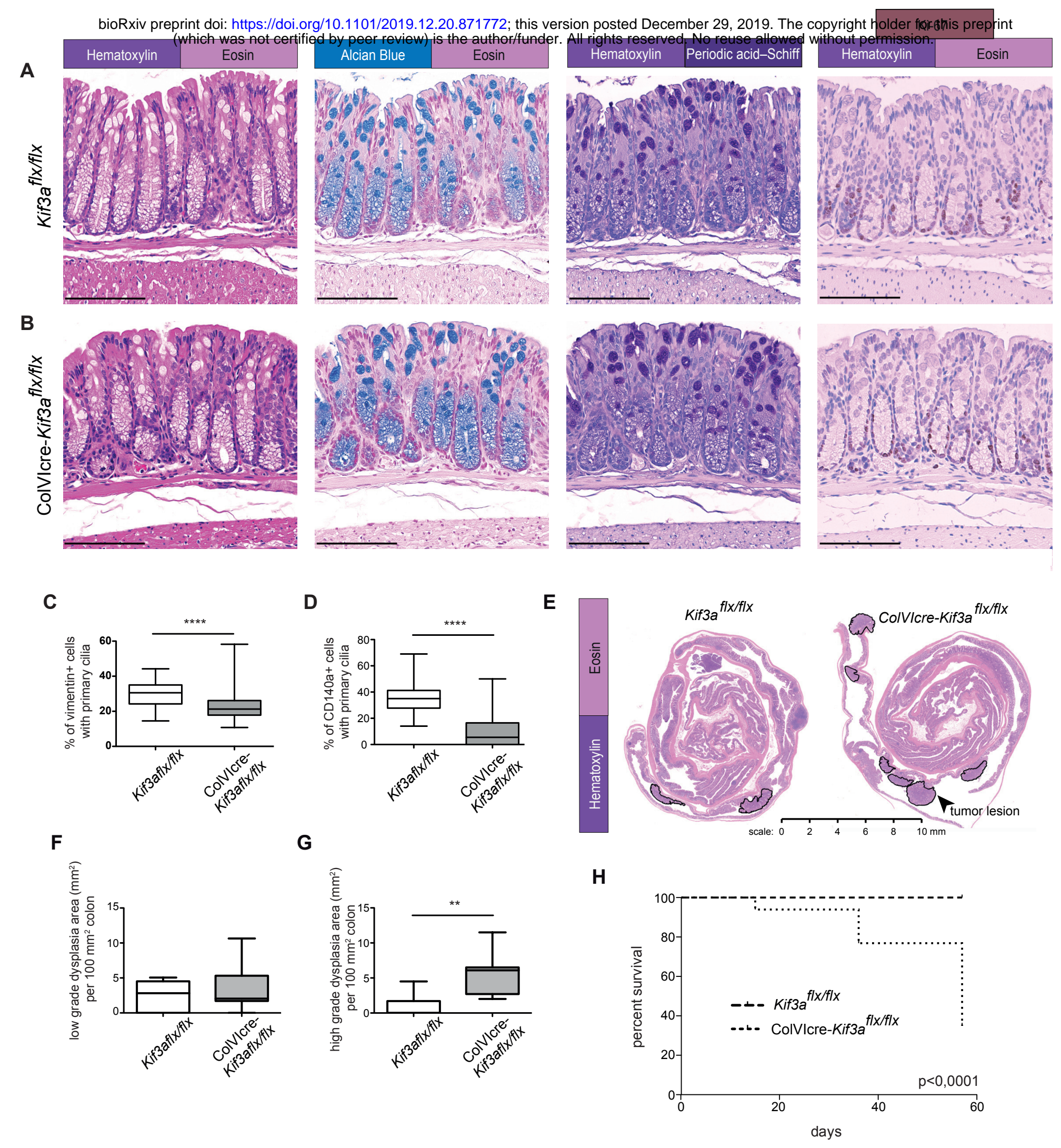


Figure 4

C

A bioRxiv preprint doi: https://doi.org/10.1101/2019.12.20.871772; this version posted December 29, 2019. The copyright holder for this preprint

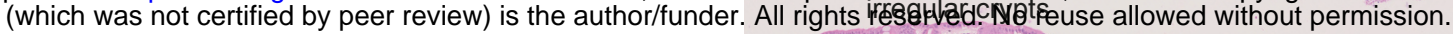

induction of inflammation

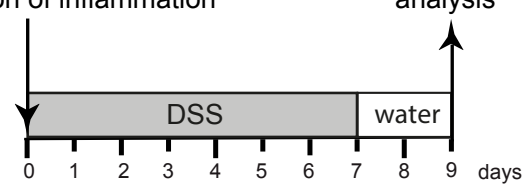

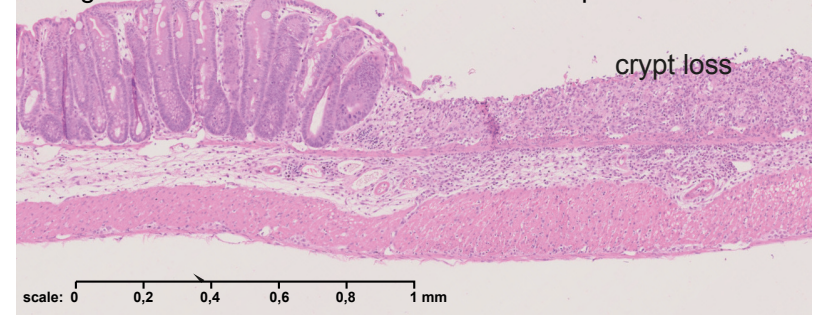

D

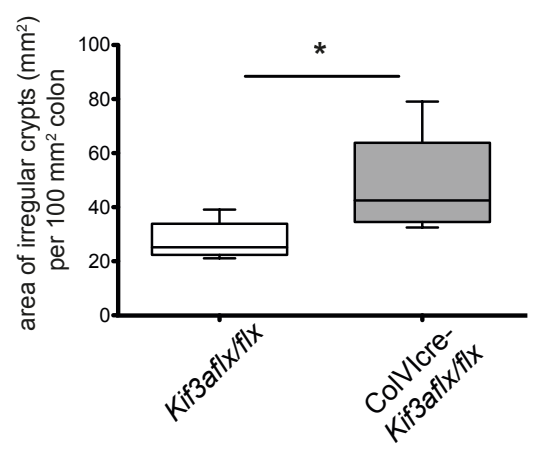

E

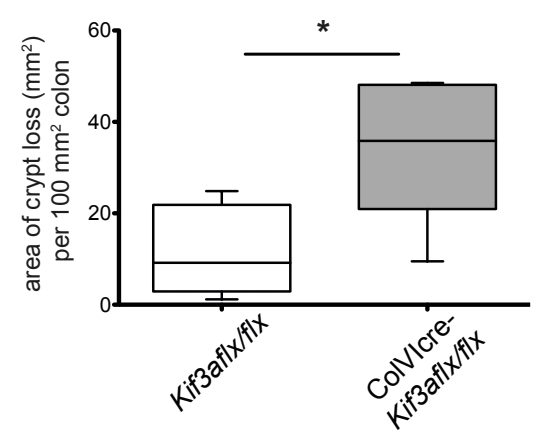

\section{$\mathbf{F}$}
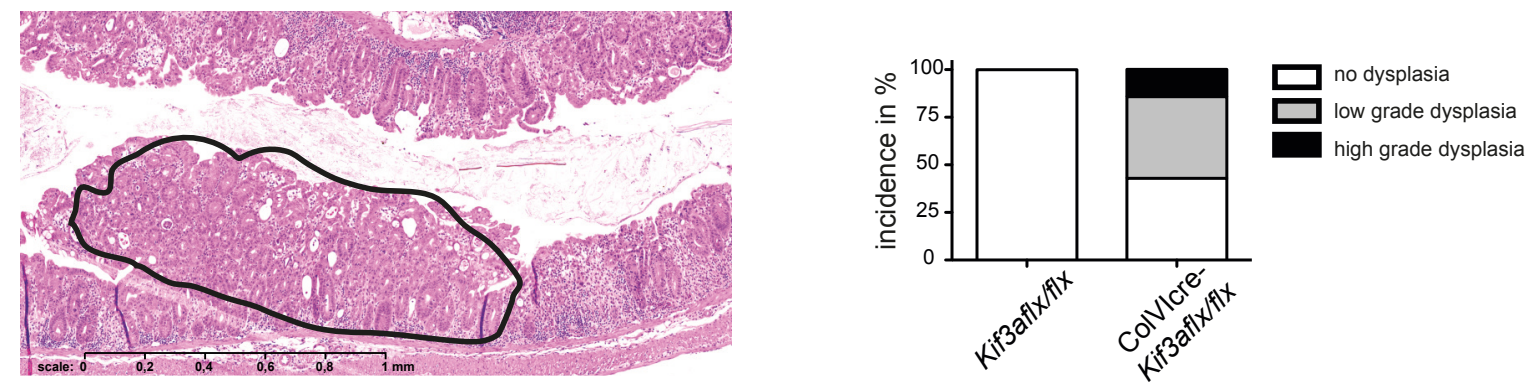

G
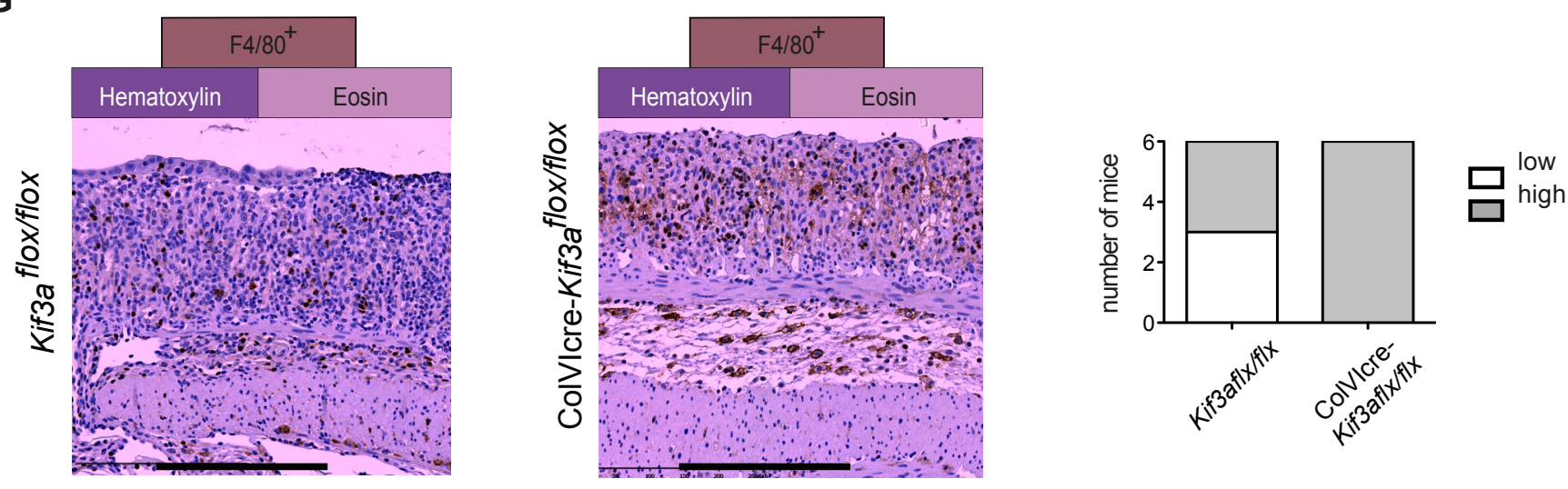

H

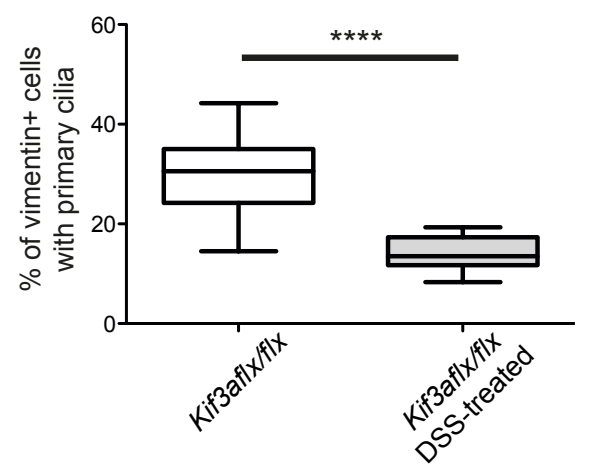

I

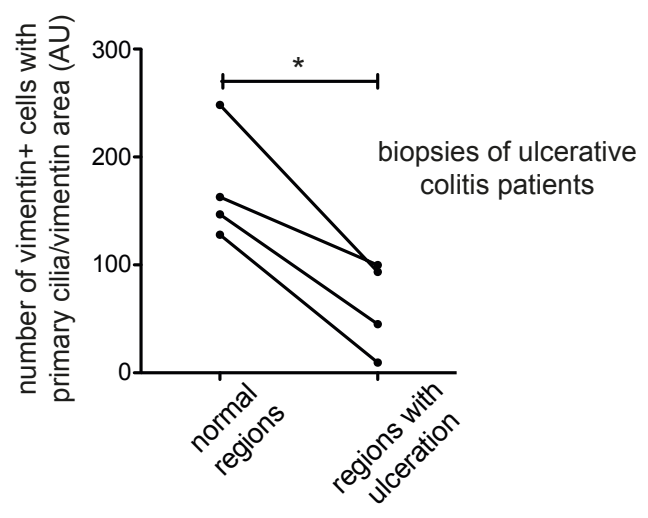


bioRxiv preprint doi: https://doi.org/10.1101/2019.12.20.871772; this version posted December 29, 2019. The copyright holder for this preprint Figure $\mathbf{5}$ (which was not certified by peer review) is the author/funder. All rights reserved. No reuse allowed without permission.

A

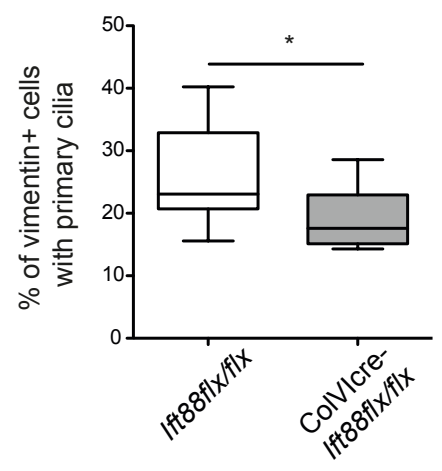

C

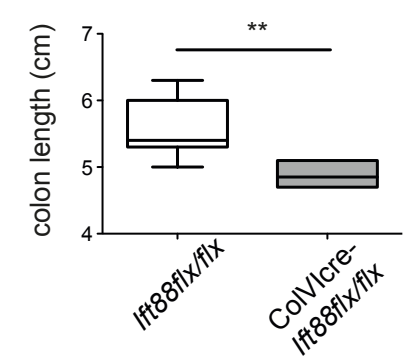

B
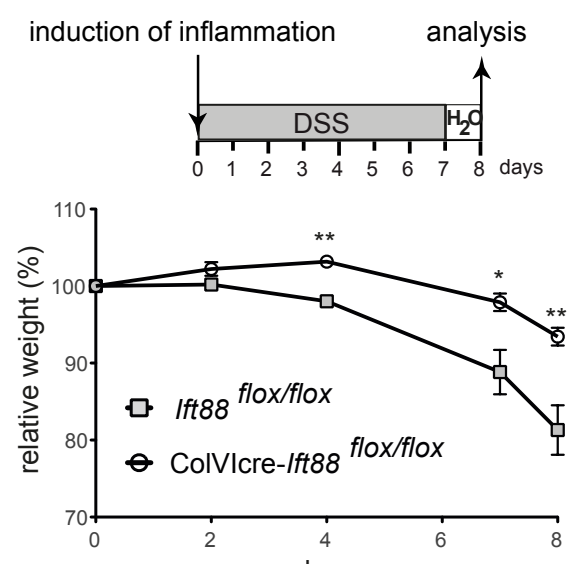

D

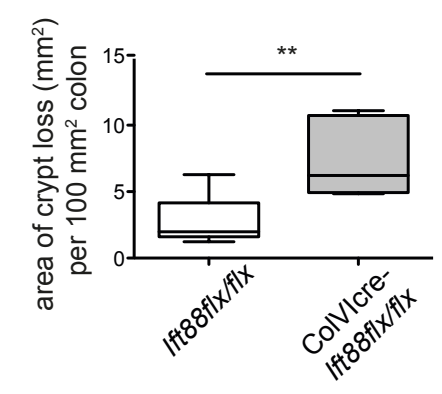

E

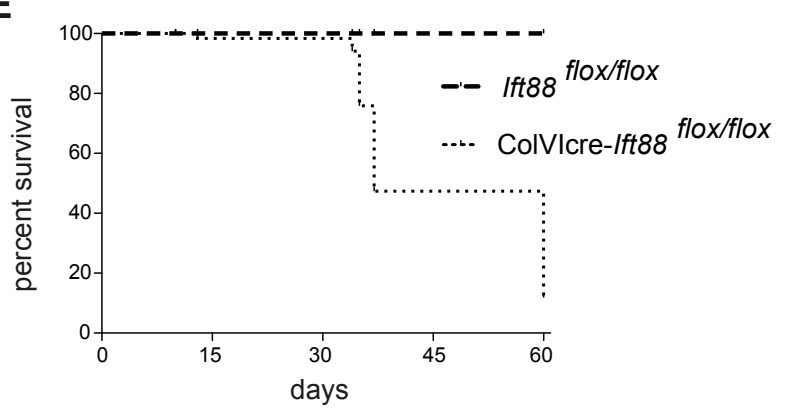




\section{Figure 6}

bioRxiv preprint doi: https://doi.org/10.1101/2019.12.20.871772; this version posted December 29, 2019. The copyright holder for this preprint (which was not certified by peerveview) is the author/funder. All rights reserved. No reuse allowed without permission.

Ift88flx/flx

A

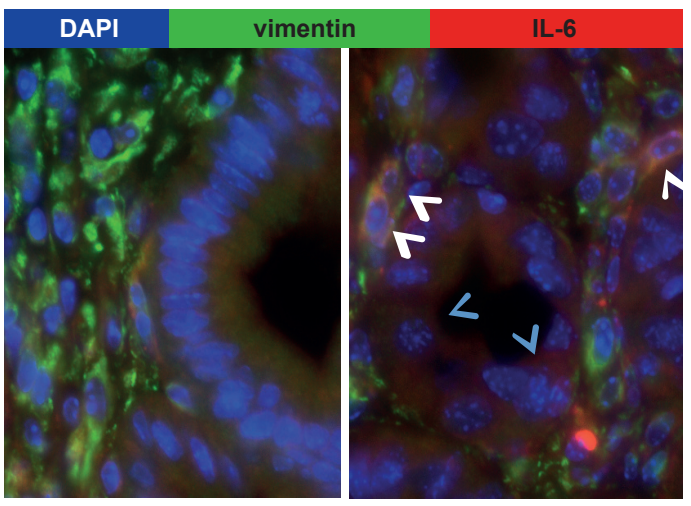

B

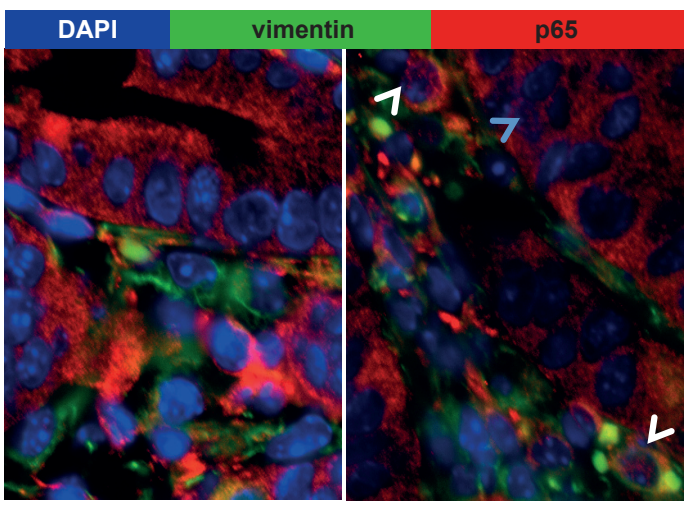

C

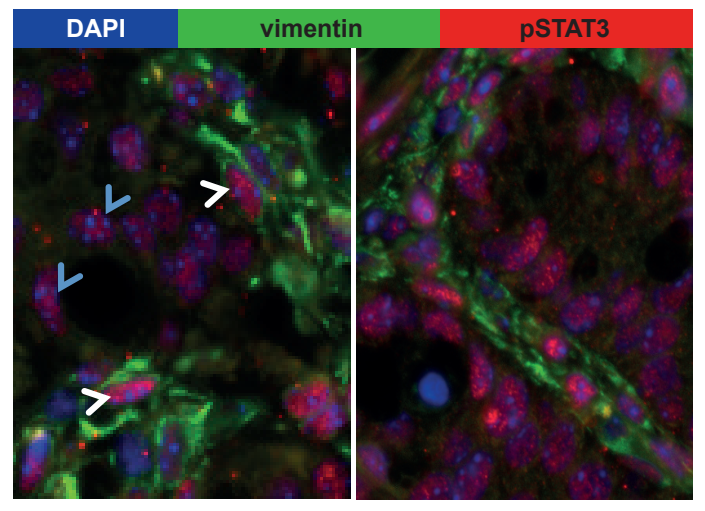

D

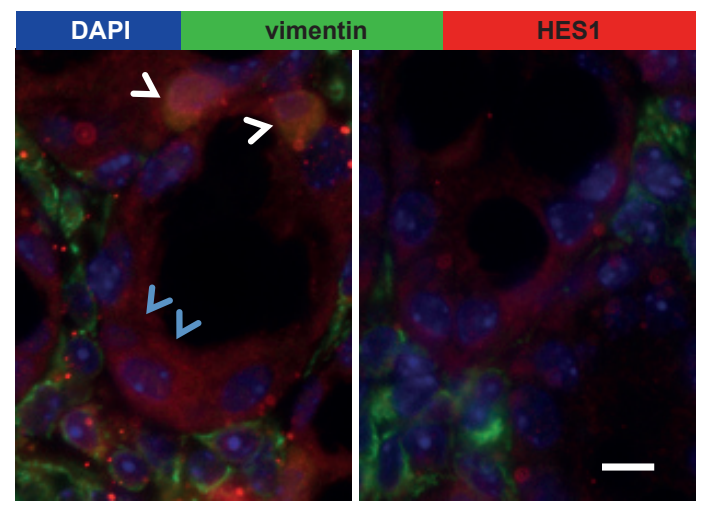

$\%$ vimentin-positive cells

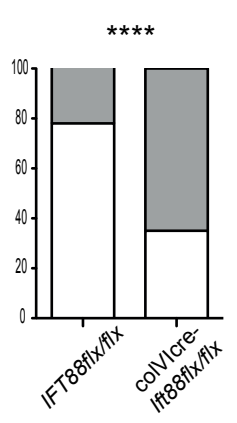

IL-6 positive cells

IL-6 negative cells $\%$ epithelial cells
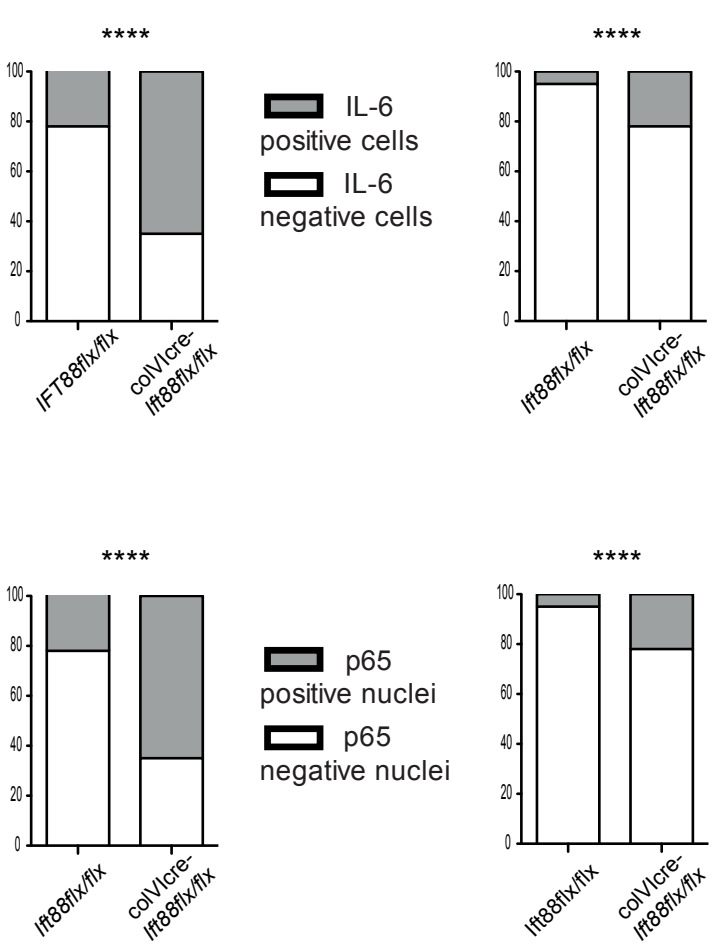

p65 positive nuclei p65 negative nuclei
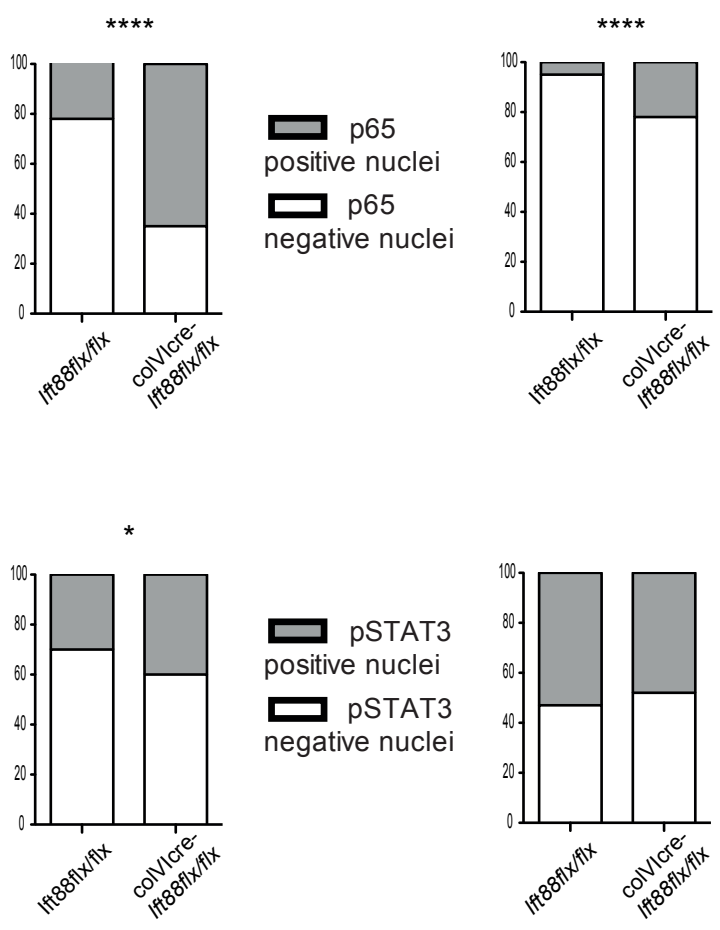

pSTAT3 positive nuclei pSTAT3 negative nuclei

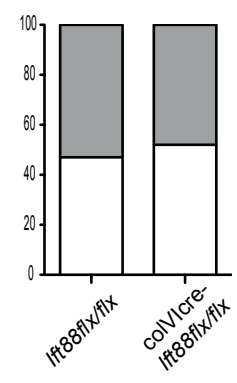
$* * * *$

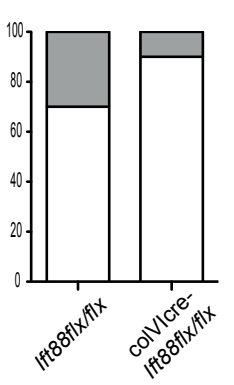

HES1 positive nuclei HES1 negative nuclei

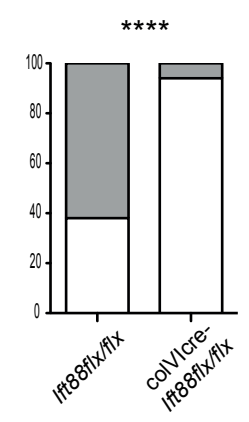




\section{Figure 7}

A

bioRxiv preprint doi: https://doi.org/10.1101/2019.12.20-871772, this version posted December 29, 2019. The copyright holder for this preprint

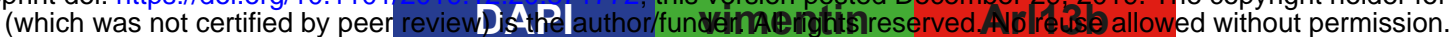
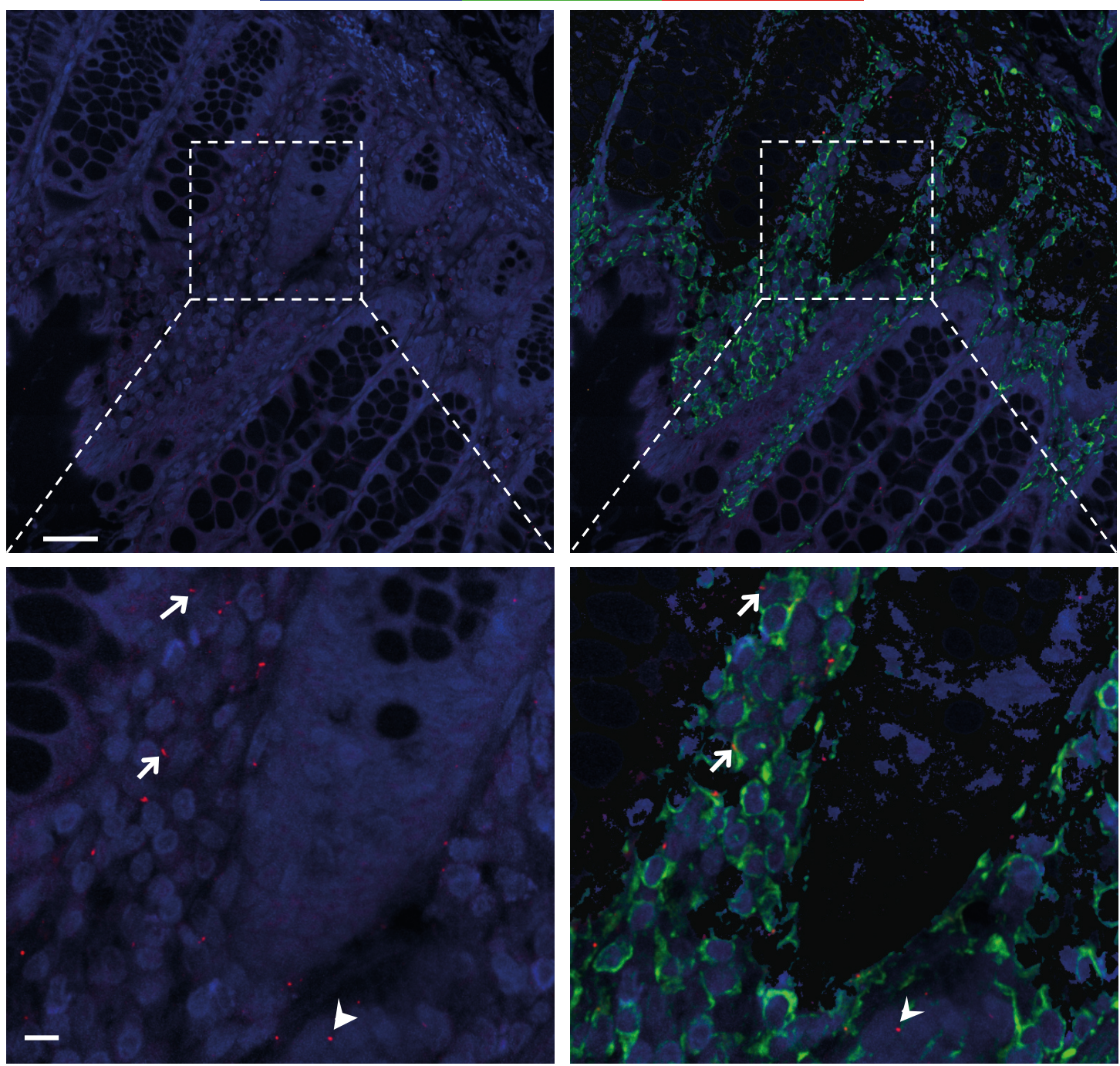

B

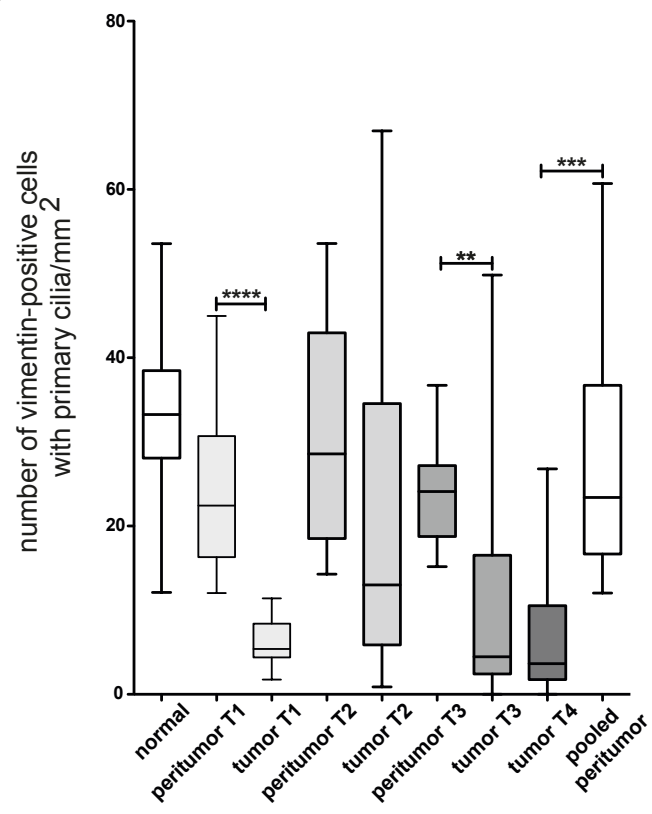

C

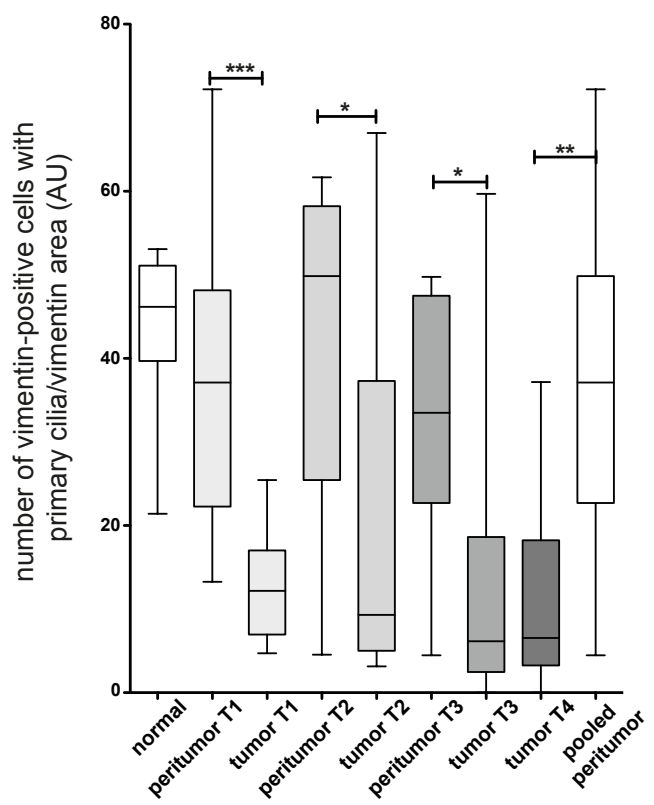

